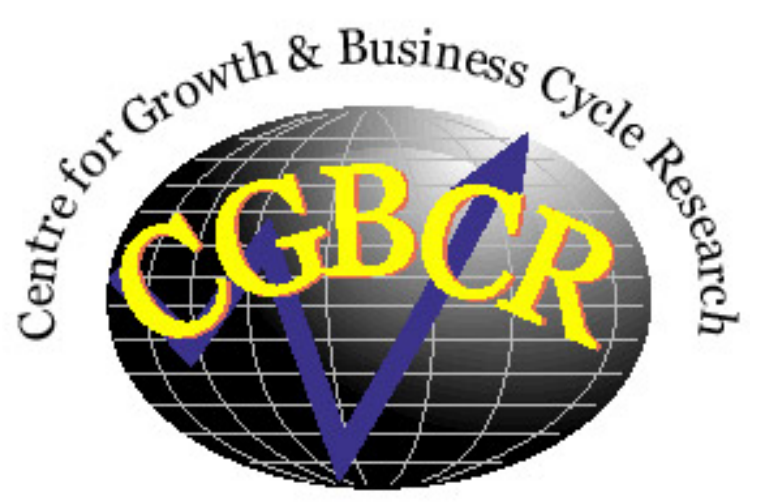

Discussion Paper Series

\title{
Public Capital, Health Persistence and Poverty Traps By
}

\section{Pierre-Richard Agénor}

Centre for Growth and Business Cycle Research, Economic Studies, University of Manchester, Manchester, M13 9PL, UK

February 2009

Number 115

Download paper from:

http://www.socialsciences.manchester.ac.uk/cgbcr/discussionpape rs/index.html 


\title{
Public Capital, Health Persistence and Poverty Traps
}

\author{
Pierre-Richard Agénor* \\ First complete draft: December 15, 2008 \\ This version: February 23, 2009
}

\begin{abstract}
Growth dynamics and health outcomes are studied in a threeperiod overlapping generations model with public capital. Reproductive agents face a non-zero probability of death in both childhood and adulthood. In addition to working, adults allocate time to their own health and child rearing. Health status in adulthood depends on health in childhood. With partial persistence in health, pure stagnation may occur. With full persistence, a stagnating equilibrium with low growth and high fertility may result from poor access to public capital. With threshold effects in health status, multiple growth regimes may emerge. A reallocation of public spending toward health or infrastructure may shift the economy from a low-growth equilibrium to a high-growth, low-fertility steady state.
\end{abstract}

JEL Classification Numbers: O41, H54, I18

${ }^{*}$ Hallsworth Professor of International Macroeconomics and Development Economics, University of Manchester, United Kingdom; and Centre for Growth and Business Cycle Research. I am grateful to Kyriakos Neanidis, Devrim Yilmaz, and most importantly Keith Blackburn for helpful discussions and comments on a preliminary draft. I bear sole responsibility, however, for the views expressed here. 


\section{Contents}

1 Introduction 3

2 Background $\quad 6$

2.1 Infrastructure and Health Outcomes . . . . . . . . . . . . 6

2.1.1 Access to Electricity . . . . . . . . . . . 6

2.1.2 Access to Safe Water and Sanitation . . . . . . . . 8

2.1.3 Roads and Transportation . . . . . . . . . . . . . 8

2.2 Childhood Health and Adult Health . . . . . . . . . . . . . . 9

2.3 Implications for Time Allocation . . . . . . . . . . . . . . . 11

3 The Model $\quad 13$

3.1 Households . . . . . . . . . . . . . . . . . 14

3.2 Firms ........................ . . . . . . . . . . . . . 17

3.3 Population and Labor Supply . . . . . . . . . . . . . 19

3.4 Health Status and Productivity . . . . . . . . . . . 19

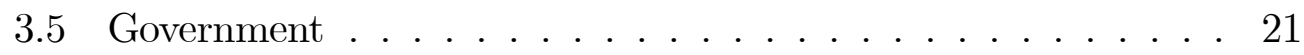

3.6 Market Clearing and Equilibrium . . . . . . . . . . 22

4 Time Allocation, Savings, and Life Expectancy 24

5 Growth and Stagnation $\quad 27$

6 Persistence in Health and Public Policy 29

7 Threshold Effects 33

8 Concluding Remarks $\quad 36$

$\begin{array}{lr}\text { Technical Appendix } & 39\end{array}$

$\begin{array}{ll}\text { References } & 48\end{array}$

$\begin{array}{ll}\text { Figures } 1 \text { to } 4 & 54\end{array}$ 


\section{Introduction}

It is now well recognized that investments in health can influence the pace of economic growth via their effects on a variety of health outcomes and healthrelated factors, including life expectancy, mortality, labor market participation and labor productivity, human capital accumulation, savings, fertility decisions, and demographic structure. Conversely, poor health may impede not only physical strength but also mental abilities, incentives to invest in education, and the ability to provide child care; as a result, it may be not only a cause of persistent poverty, but also an outcome of poverty. There is much evidence to support this two-way causality; Lorentzen, Mcmillan and Wacziarg (2008), for instance, found a bidirectional link between life expectancy and income. Finlay (2007), in a cross-country study, found that growth, education, and health are determined simultaneously - a result that also illustrates the importance of accounting for the indirect effect of health on human capital accumulation in measuring its impact on growth.

From the perspective of development theorists, a natural implication of the empirical evidence is that growth, development, and health outcomes (as well as their implications for demographic variables) should be studied jointly to understand how stagnation and poverty traps may emerge, and what to do to escape from them. This recognition has led to a number of recent contributions, based on overlapping generations (OLG) models, in which life expectancy (or more precisely the probability of dying) is endogenized. Most noteworthy among them are Blackburn and Cipriani (2002), Kalemli-Ozcan (2003, 2008), Chakraborty (2004), Cervellati and Sunde (2005), Hashimoto and Tabata (2005), Finlay (2006), Hazan and Zoabi (2006), Bhattacharya and Qiao (2007), Tang and Zhang (2007), Castelló-Climent and Doménech (2008), and Osang and Sarkar (2008). In an important contribution, Blackburn and Cipriani (2002) developed a three-period OLG in which educational investments are pursued simultaneously with working and child bearing. This approach, however, may be less relevant for developing countries, where there is more sequentiality between education and child bearing. More importantly, the survival probability depends only on human capital; in the model, parents' choice of education of their children determines only indirectly the longevity of their offspring and their income. As a result, the survival rate is exogenous from the point of view of the marginal decisions of individuals. ${ }^{1}$

\footnotetext{
${ }^{1}$ In an Appendix to their paper, Blackburn and Cipriani (2002) consider the case where
} 
Chakraborty (2004) developed an OLG model in which life expectancy is a linear function of public health expenditures, which are funded by a tax on wage income. In turn, agents' wage income depends on the society's rate of capital accumulation, which is increasing in longevity. Interactions between life expectancy and savings generate therefore multiple equilibria and healthincome traps: a short life expectancy slows down capital accumulation and economic growth, while a lower income shortens life expectancy - which in turn lowers savings and investment. Because wages rise continuously with the level of output per worker, health status rises perpetually. In addition, as in Blackburn and Cipriani (2002) and Hashimoto and Tabata (2005), health status remains independent of private decisions.

By contrast, Finlay (2006), Bhattacharya and Qiao (2007), and Tang and Zhang (2007) all relate longevity to private spending on health. In particular, Finlay (2006) uses a model similar to Chakraborty (2004), but where health expenditures are chosen by individuals (rather than by a public health system) and where human capital is the engine of (endogenous) growth. In her model, private agents therefore "choose" indirectly their survival probability by setting the level of health expenditure. However, decision rules cannot be explicitly derived and numerical methods must be used to study the economy's equilibrium. More generally, neither one of these three studies recognizes that health status may depend on a variety of factors (beyond human capital), including time allocated to one's health and access to public services - a particularly critical issue in developing countries.

This paper contributes to this literature by developing an OLG model that departs from existing contributions in several important ways. First, although fertility choices are endogenous, it abstracts from human capital accumulation. Unlike existing models, I therefore also abstract from the conventional "quantity versus quality" of children that arises from the fertility and educational choices of parents. Instead, the endogeneity of life expectancy is related directly to health status, rather than human capital as for instance in Blackburn and Cipriani (2002) or Castelló-Climent and Doménech (2008). On the one hand, there is indeed evidence suggesting that better educated individuals are more able to adopt healthy lifestyles and to inspire the same type of behavior on their children. Mullahy and Robert (2008), for instance, found that more educated individuals not only

public policy also affects life expectancy. However, this does not change the fact that the survival rate remains exogenous from the perspective of individual decisions. 
work more but also exercise more. Silles (2009) found evidence of causality from schooling to health for the United Kingdom. On the other, however, there are a number of examples to suggest that better education does not necessarily lead to better health. Smoking and alcoholism are equally common in groups with vastly different levels of education; and obesity appears to be a characteristic of mostly developed (and better educated) countries. ${ }^{2}$

Health status itself is here taken to depend on a variety of variables, including the time that individuals spend taking care of themselves. Quite naturally, such decisions are treated as endogenous. Unlike a common assumption in the literature, I also assume that time spent on child rearing is productive (albeit indirectly), because it helps to improve a child's healthand hence health later in life. Thus, time allocated to child care is treated endogenously as well. At the same time, the model assumes that it is "effective" labor that is used in production; and individuals can provide effective labor services only if they are healthy. Thus, by enhancing productivity, health status influences growth indirectly.

Second, in the model the engine of long-run growth is the accumulation of public capital in infrastructure - a key constraint to growth in poor countries. The model accounts for various sources of externalities associated with public capital, not only in terms of the production of goods, but also in terms of the production of health services and the efficiency of time use. Consequently, the paper takes a broader perspective on the relationship between health, infrastructure, and growth, in line with the recent literature on the macroeconomic effects of health services. ${ }^{3}$ As it turns out, this is quite important for assessing the effect of changes in life expectancy on growth. Third, the paper accounts for the fact that health outcomes in childhood may affect health outcomes in adulthood. As a result, health status displays persistence, as in Osang and Sarkar (2008). However, in a critical contrast to that paper, here agents also allocate time to caring for themselves and their children, and therefore internalize the impact of these decisions. In addition, health status is not necessarily constant in the steady state.

The remainder of the paper is organized as follows. Section II provides a more detailed background on the links between access to infrastructure and

\footnotetext{
${ }^{2} \mathrm{~A}$ more general approach, of course would be to consider jointly education and health status as determinants of life expectancy. However, this would complicate significantly the analysis and would detract from the main contribution of this paper.

${ }^{3}$ See for instance Agénor (2008) and Agénor and Neanidis (2006). These contributions, however, do not deal with demographic issues and time allocation.
} 
health, and the impact of health status in childhood on health outcomes in adulthood. The key point is that both of these links have critical implications for the way individuals allocate their time between working, child rearing, and taking care of one's health. Section III brings together these different elements in the context of a 3-period OLG model with public capital. Section IV solves for the optimal household decision rules. Section V derives the balanced-growth path under the assumption of partial persistence in health status and constant survival rates, and discusses the properties of the model. Section VI considers the case where adult health status is not stationary. Section VII considers threshold effects associated with health status. I also address the issue of whether an increase in public spending may allow a country to escape from a low-growth trap. The last section of the paper offers some concluding remarks.

\section{Background}

As background motivation to the model developed in this paper, this section provides a brief review of the evidence on two key issues: the impact of infrastructure on health outcomes, and the link between childhood health and health outcomes in adulthood. I then examine the implications of these links for understanding constraints and incentives at the individual level regarding time allocation, and potential lessons for models of growth and development.

\subsection{Infrastructure and Health Outcomes}

A wide range of recent microeconomic studies have documented the fact that infrastructure may affect health outcomes through a variety of channels. For convenience, these effects can be grouped according to whether they relate to access to electricity, access to water and sanitation, and access to road and transportation. ${ }^{4}$

\subsubsection{Access to Electricity}

The health benefits from electrification may operate through a number of channels (World Bank (2008, p. 42)): improved functioning of health facilities; better health from cleaner air as households reduce use of polluting

\footnotetext{
${ }^{4}$ See Agénor (2009) for a more comprehensive overview of the empirical evidence.
} 
fuels for cooking, lighting, and heating; improved health knowledge through increased access to media; and better nutrition from improved knowledge and storage facilities from refrigeration.

First, availability of electricity is essential for the functioning of hospitals and the delivery of health services. Vaccines, for instance, require continuous and reliable refrigeration to retain their effectiveness. Second, by reducing the cost of boiling water, access to electricity may help to improve hygiene and health. Third, getting access to clean energy for cooking in people's homes (as opposed to smoky traditional fuels, such as wood, dung, crop residues, and charcoal) improves health outcomes, by reducing indoor air pollution and the incidence of respiratory illnesses and child mortality. ${ }^{5}$ Improvements in indoor air quality can also come about through changes in lighting source. Kerosene lamps emit particles that cause air pollution; the extra risk of respiratory sickness from exposure to this source of pollution translates into a loss of adult work averaging 3 days per year, and an additional under-five mortality of 2.2 per 1,000 (World Bank (2008, p. 43)). Thus, substituting electric lighting for kerosene lamps may have sizable health benefits as well.

Fourth, to the extent that electrification promotes access to media (television and radio), it also helps to improve health knowledge and to increase awareness of health issues. This in turn translates into greater use of modern contraceptives and child immunization. A World Bank study of Bangladesh for instance found a significant impact of household electrification on mortality, through reduced fertility. Other studies have documented the fact that children born in households using clean fuels (electricity and liquid gas) have lower infant mortality rates (World Bank (2008)). In a study based on demographic and health survey data for more than 60 low-income countries, Wang (2003) found that access to electricity significantly reduces child mortality, independently of any income effect. These results may be due to the fact that access to electricity, in addition to reducing the risk of respiratory infections, facilitates refrigeration of food and boiling of water, which are important to

\footnotetext{
${ }^{5}$ Indoor burning of solid fuels emits a substantial amount of particulate matter and gaseous pollutants like carbon monoxide, nitrogen dioxide, and hydrocarbons. Combustion of wood, one of the cleaner biomass fuels, emits 50 times more household pollution than do gas stoves (Smith et al. (2000)). Over 3 billion people worldwide use solid fuels for cooking, boiling water, lighting, and heating (Rehfuess et al. (2006)). According to World Bank data, indoor air pollution causes 1.6 million premature deaths every year and afflicts nearly half of the world's population, predominantly the rural poor. This makes it the second leading environmental health threat in the world.
} 
reduce the incidence of infectious diseases among young children. ${ }^{6}$

Finally, electricity may also have an indirect effect on health through education. Because the burden of fuel collection falls primarily on women and girls in poor countries, the probability of a child attending school decreases with hours spent collecting wood. In addition to direct, adverse longer-run effects on growth, reduced school attendance may hamper the transmission of health knowledge and thus contribute to poor health outcomes.

\subsubsection{Access to Safe Water and Sanitation}

It is widely acccepted that the lack of safe drinking water and a scarcity of hygienic sanitation services are primary causes of disease and poor health in many low-income countries. Water-borne diseases (such as typhoid, cholera, dysentery, gastroenteritis and hepatitis), as well as water-based diseases (such as scistosomiasis and guinea worm) are common. For instance, deaths from diarrhea, a direct result of poor water quality, are the highest in Sub-Saharan Africa. Access to clean water and sanitation infrastructure may therefore have a large impact on malnutrition and infant mortality (see Gertler (2005)). This is indeed what the evidence suggests; for instance, using a multi-country, city-level database of urban indicators, Shi (2000) found that improved access to urban potable water and sewerage connections reduces child mortality, whereas Wang (2003) found that access to piped water is particularly important in rural areas.

\subsubsection{Roads and Transportation}

Improved road and transportation infrastructure may affect health outcomes also through several channels. First, better transportation networks contribute to easier access for patients to health facilities and health care, particularly in rural areas. They also make it easier to transport the sick (especially children) in case of emergency, to carry health medicines where they are needed, and to facilitate movements of medical personnel between rural and urban areas - thereby improving the quality of health services. ${ }^{7}$ Data on

\footnotetext{
${ }^{6}$ As noted by Wang (2003, P. 294), the health impact of access to electricity is likely to be stronger in urban areas, where infectious diseases are more likely to spread as a consequence of greater population density.

${ }^{7}$ It is worth noting, however, that constraints to access to medical facilities relate not only to distance and difficult terrain (which can be mitigated by better infrastructure),
} 
national demographic and health surveys in Sub-Saharan Africa show that a majority of women in rural areas rank distance and inadequate transportation as major obstacles in accessing health care (see African Union (2005)). In Morocco, a program developed in the mid-1990s to expand the network of rural roads led to a sizable increase in visits to primary health care facilities and clinics (see Levy (2004)). Using cross-section regressions, Wagstaff and Claeson (2004) found that road infrastructure - as measured by the length of the paved road network - had a significant effect on a number of health indicators, such as infant and female mortality rates. Second, to the extent that lack of public transport inhibits opportunities to attend school, and that the transmission of knowledge about health risks operates partly through the education system, improved access to transportation may also generate an indirect benefit through increases in schooling ratios.

\subsection{Childhood Health and Adult Health}

There is growing evidence suggesting that late life health is the outcome of a cumulative process of exposure to health risks in childhood, especially infectious diseases in the first years of life. By determining health outcomes later in life, health in childhood may therefore play a critical role in the determination of socioeconomic status in adulthood (Strauss and Thomas (1998)). Indeed, studies have shown that hunger and infections in early childhood result in stunting, which in adulthood often brings about substantial income losses. Using data for the United States, Case, Lubotsky, and Paxson (2002) found that on average differences in the health status of children between lowerand upper-income households become more pronounced with age, suggesting a possible accumulation of adverse health conditions over time. Case, Fertig, and Paxson (2005), using a 1958 British birth cohort who were followed prospectively into their adult years, found that children who experience poor health have on average significantly poorer health - as well as lower educational attainment and lower earnings - as adults. Using data from the Panel Survey of Income Dynamics in the United States covering 30 years, Smith (2008) found that poor childhood health has a quantitatively large effect on individual earnings and labor supply, as well as family income and household

but also to cost and income, which depend on growth and redistribution policies. Greater access to infrastructure may also have an adverse effect on health outcomes; in some countries, the spread of AIDS has been attributed in part to greater gatherings of female sex workers operating along road corridors and seaports. 
wealth. Paxson and Schady (2007) found that health measures such as height for age and weight for age are positively related to language development (a measure of cognitive ability) in a study based on Ecuadorian data.

Health in childhood may also affect health and income in adulthood through education (see Gertler and Zeitlin (1996, 2002) Mayer-Foulkes (2005), Miguel (2005), and surveys by Behrman (1996) and Currie (2008)). Pain, fatigue, and malnutrition can reduce the ability to concentrate and to learn. Illness can crowd out other activities that might be beneficial to child development. Some health conditions, such as attention-deficit hyperactivity disorder or deafness for instance, can also have a direct, negative impact on cognitive or verbal ability, respectively. Measures of child development, such as cognitive and verbal ability, have been shown to be good predictors of various measures of human capital in adulthood, such as earnings and employment (see Currie (2000)). ${ }^{8}$

Salm and Schunk (2008) provide one of the first studies to quantify the extent to which gaps in child development between socioeconomic groups can be explained by differences in child health. In a study of German data, they found that 18.4 percent of the gap in cognitive ability and 64.8 percent of that in verbal ability between children of college educated parents and less educated parents can be attributed to poor initial health conditions. ${ }^{9}$ The results of Kohler and Soldo (2004), who found in a study of Mexico that individuals with low levels of education have higher mortality rates than better-educated individuals, may also be due to the fact that the level of education varies positively with health status.

The link between childhood health and health in adulthood can operate in the opposite direction as well. There is evidence suggesting that cognitive and physical impairments of children may begin in utero, due to inadequate nutrition and poor health of the mother. According to estimates reported by Bloom and Canning (2005), for instance, an estimated 30 million infants are born each year in developing countries with impaired growth due to poor nutrition during fetal life. More generally, the health of parents may also affect the health of their children, after they are born, to the extent that it

\footnotetext{
${ }^{8}$ At the same time, child development may be also related to a child's socioeconomic background (see Taylor et al. (2004)). If so then children from disadvantaged families may fall behind early in life and may be unable to catch up later.

${ }^{9}$ See also Oreopoulos et al. (2008), who found in a study for Canada that poor infant health is a strong predictor of future education outcomes.
} 
determines their physical and mental ability to provide child care. ${ }^{10}$

\subsection{Implications for Time Allocation}

Lack of access to basic infrastructure imposes significant constraints on the allocation of time in poor countries, especially women in rural areas. ${ }^{11}$ Fuel collection imposes a time burden of up to 8 hours a week, usually mainly on women. In Malawi for instance, more than 90 percent of households collect and use wood as the main source of cooking energy (Nankhuni and Findeis (2003)). In some countries collection times have risen appreciably, as locally available firewood as become increasingly scarce. Indeed, dependence on wood for fuel has contributed to significant deforestation, forcing residents to travel even farther to collect wood - thereby increasing the amount of time allocated to that activity. Reducing the time burden associated with fuel collection may therefore lead to a sizable reallocation of time to other activities.

Similarly, because the provision of water is poor or non-existent in many poor countries (especially in rural areas), a substantial amount of time must be allocated to water collection from either community sources (such as wells or taps) or open access areas (such as rivers). In most countries the burden of provision of these services to the household falls again mostly on female members. In Sub-Saharan Africa, women spend between 0.9 and 2.2 hours per day collecting water and fuel wood (see Weiss (1999)). Improved availability of water closer to communities (through pipes or handpump wells) would generate significant savings in collection time and benefit women disproportionately. In turn, some portion of time savings can be used not only for productive activity but also for rearing children and taking care of one's health, which may also generate indirect benefits in terms of growth.

Lack of roads and transportation imposes a significant burden on time allocation as well - especially in rural areas. Household members, for instance, may be forced to spend a lot of (unremunerated) time travelling to work on foot. In such conditions, the provision of rural roads may lead to significant time savings. Finally, infrastructure may also improve the efficiency of time allocated to specific activities. Greater access to electricity for instance, by improving the ability to boil water, raises the efficiency of time allocated by

\footnotetext{
${ }^{10}$ See for instance the results of Powdthavee and Vignoles (2008) for Britain.

${ }^{11}$ See Ilahi (2000) for a review of the literature on the intra-household allocation of resources in developing countries.
} 
parents (or more specifically mothers) to home production and child rearing. This is quite important because the time allocated to child care is quite significant in developing countries - around one hour a day in most cases, but between one and two hours in countries like Bangladesh, Botswana, Kenya, and the Philippines (see Brown and Haddad (1995)) and up to three hours in a country like Nicaragua (see Ilahi (2000)). Similarly, greater access to transportation also improves the efficiency of time allocated to taking care of children's health and parents' own health - by making it easier and faster to get to a medical facility. ${ }^{12}$

The foregoing discussion suggests that, when assessing the impact of infrastructure on health outcomes and growth, it is important to account not only for the direct effects, but also for the indirect effects that may operate through time allocation. If indeed greater access to infrastructure allows a more efficient use of time, understanding what households do with these time savings becomes critical to health and growth. This is because individuals may consider not only allocating more "raw time" to market work as an alternative, but also increasing time spent in home production, taking care of one's health (which includes travel time to a medical facility, as well as time spent exercising), and caring for children's health. Both of the latter activities would affect health status in adulthood, and therefore productivity, wages, and growth. ${ }^{13}$ In addition, health status (rather than human capital, as discussed earlier) affects also directly life expectancy, and thereby investment and savings behavior - which in turn may affect growth. I now turn to a formal analysis that captures these interactions.

\footnotetext{
${ }^{12}$ As noted by the World Bank (2008), greater access to electricity makes possible longer waking hours; household repondents to a survey reported that they stay up, on average, an additional one to two hours, with much of that extra time allocated to watching television. To the extent that this is a source of health-related knowledge, this can bring (as noted earlier) substantial health benefits.

${ }^{13}$ In their empirical analysis, Kooreman and Kapteyn (1987) distinguished between eight categories of time use. However, they did not identify time spent taking care of one's health among them; neither did they discuss the implications of time allocation for health status and growth.
} 


\section{The Model}

Consider an OLG economy where one marketed good is produced and individuals live (at most) for three periods: childhood, adulthood (or middle age) and retirement (or old age). The good can be either consumed in the period it is produced or stored to yield capital at the beginning of the following period. Each individual is endowed with one unit of time in childhood, two units in middle age, and zero unit in old age. Children devote all their time to the production of a home good, which produces no direct utility. They depend on their parents for consumption and health care. All individuals supply inelastically one unit of labor in middle age; the only source of income is therefore wages in the second period of life, which serves to finance consumption in adulthood and old age. Savings can be held only in the form of physical capital. Agents have no other endowments, except for an initial stock of physical capital, $K_{0}^{P}$ at time $t=0$, which is held by an initial generation of retirees.

In adulthood, and in conformity with the "Virgin Mary" hypothesis, each individual bears $n_{t}$ children, who are born with the same innate abilities and the same initial health status. However, keeping children healthy involves a cost, both in terms of the parent's time, and spending on marketed goods (medicines, etc.). Adults must decide on the allocation of their non-work unit of time not only to child rearing, but also to taking care of their own health, and leisure.

At the beginning of the first period of life and the end of the second, there is a non-zero probability of dying. Both probabilities are initially taken as given. The health status of children and adults are taken to depend on different determinants, in line with the evidence of Cutler, Deaton, and LlerasMuney (2006). For children, health status depends on the effective time that parents allocate to rearing their offspring, on access to infrastructure services, and on the parent's health. The latter effect is consistent with the evidence, discussed earlier, suggesting that parents' physical and mental health (beyond short-term stress and strain) affects their children's well-being. ${ }^{14}$ In addition, access to infrastructure also affects the efficiency of parents' time allocated to child rearing.

For adults, health status is taken to depend on the effective time spent

\footnotetext{
${ }^{14}$ Alternatively, it could be assumed that cognitive and physical impairments of children may begin in utero, due to inadequate nutrition and poor health of the mother.
} 
caring about one's health and health status in childhood. There is therefore "state dependence" in health outcomes. This specification is consistent with the evidence discussed earlier, according to which children who experience poor health have on average significantly poorer health as adults.

In addition to individuals, the economy is populated by firms and an infinitely-lived government. Firms produce marketed goods using private capital, labor, and public capital in infrastructure as inputs. The specification of health status and the goods production technology therefore bring to the fore some of the key externalities associated with infrastructure, as discussed in the previous section.

The government invests in infrastructure and spends on health and some unproductive services. All government services are provided free of charge. Public capital is nonexcludable but partially rival, due to congestion effects. It taxes only the wage income of adults. It cannot borrow and therefore must run a balanced budget in each period. Finally, all markets clear and there are no debts or bequests between generations.

\subsection{Households}

At the beginning of their adult life in $t+1$, each individual bears $n_{t+1}$ children. ${ }^{15}$ Raising a child involves two types of costs: parents spend $\varepsilon_{t+1}^{R} \in(0,1)$ units of time on each of them, namely to take care of the child's health (breast feeding, taking children to medical facilities for vaccines, etc.). Each adult allocates $\varepsilon_{t+1}^{R} n_{t+1}$ units of time to that activity. Second, raising children involves costs in terms of marketed goods. These costs relate to feeding children, taking them to medical facilities, buying medicines, etc. Specifically, each individual spends a fraction $\theta \in(0,1)$ of his adult disposable income on each child's health. Thus, although access to "out of home" health services per se is free, families face a cost in terms of foregone wage income and consumption.

Let $y_{t+1}$ denote the individual's net income in $t+1$; the total cost of raising $n_{t+1}$ children - should all of them survive - is thus given by the sum of the opportunity cost in terms of foregone wage earnings, and the opportunity cost in terms of foregone consumption, that is, $\left(\varepsilon_{t+1}^{R}+\theta\right) n_{t+1} y_{t+1}$. Thus, in standard fashion (see for instance Barro and Becker (1989) and Galor

\footnotetext{
${ }^{15}$ For tractability, the number of children is assumed to be continuous. Integer restrictions are thus neglected.
} 
and Weil (2000)), the existence of these costs creates a trade-off between the quality and quantity of children - with respect to health, rather than education.

In addition to raising their children and supplying labor inelastically to firms, adults allocate time in proportion $\varepsilon_{t+1}^{H}$ to taking care of their own health needs, which includes seeking medical treatment (that is, the time allocated to going to hospital or visit a doctor) personal hygiene, and exercise. Doing so involves no direct income loss. ${ }^{16}$

The probability of survival from childhood to adulthood (at the beginning of period $t+1)$ is denoted by $p_{t+1}^{C} \in(0,1)$, whereas the probability of survival from adulthood to old age (at the end of period $t+1$ ) is denoted by $p_{t+1}^{A} \in$ $(0,1)$. For tractability, I do not account explicitly for the random nature of the number of surviving children and adults; the number of survivors in each age group is simply given by the expected number of survivors. To avoid convergence of population size toward zero, I also assume that $p_{t+1}^{C} n_{t+1} \geq 1$.

There is an actuarially fair annuity market that channels savings to investment in physical capital, $K_{t}^{P}$, for production in the next period. With the annuity market, old-age survivors share the savings plus interest left by savers who die in adulthood. ${ }^{17}$ Let $r_{t+2}$ denote the rental rate of private capital; the effective rate of return to saving is thus $r_{t+2} / p_{t+1}^{A}$.

Assuming that consumption of children in the first period of life is subsumed in their parents' consumption, expected lifetime utility at the beginning of period $t+1$ of a (surviving) agent born at $t$ is specified as ${ }^{18}$

$$
\begin{aligned}
U= & \ln c_{t+1}^{t}+\eta_{L} \ln \left(1-\varepsilon_{t+1}^{H}-p_{t+1}^{C} n_{t+1} \varepsilon_{t+1}^{R}\right) \\
& +\eta_{N} \ln p_{t+1}^{C} h_{t+1}^{C} n_{t+1}+p_{t+1}^{A} \frac{\ln c_{t+2}^{t}}{1+\rho}
\end{aligned}
$$

\footnotetext{
${ }^{16}$ Adding a proportional cost in terms of net income, as was done for health care provided to children, is straightforward.

${ }^{17}$ This specification is adopted by Zhang and Zhang (2005) for instance, and many others. Alternatively, it could be assumed that the saving left by agents who fail to survive to old age is confiscated by the government, who spends it for unproductive purposes. If so, however, the life-cycle effect of changes in the adult survival rate would disappear.

${ }^{18}$ Although uncertainty is not explicitly accounted for in this framework, the discounted lifetime utility of a generation- $t$ individual at time $t$ depends on the "expected" rate of return on capital at time $t+2$; hence ex ante the lifetime utility is "expected." Note also that if the individual does not survive to adulthood, then the maximization problem becomes degenerate.
} 
where $c_{t+j}^{i}$ denotes consumption of generation $i$ individuals at date $t+j$ and $\rho>0$ the discount rate. The term $p_{t+1}^{C} h_{t+1}^{C} n_{t+1}$ is equal to actual family size $p_{t+1}^{C} n_{t+1}$-which differs from fertility (the number of children per individual), $n_{t+1}$, because the child survival rate is less than unity-multiplied by the health status of a child, $h_{t}^{C}$. In the standard literature, parents derive utility from the "raw" production of offspring. Here, however, it is the expected number of healthy children that matters.

The term $1-\varepsilon_{t+1}^{H}-p_{t+1}^{C} n_{t+1} \varepsilon_{t+1}^{R}$ measures leisure in adulthood, whereas coefficients $\eta_{N}$ and $\eta_{L}$ measure the individual's relative preference for leisure and surviving healthy children. Although adult health status does not provide any direct utility benefit to the household, as discussed later it affects it indirectly through wages. ${ }^{19}$

Suppose that child mortality occurs only at the beginning of the period, so parents incur no rearing costs for children who die before adulthood. ${ }^{20}$ Because there is no consumption in childhood, the period-specific budget constraints are

$$
\begin{gathered}
c_{t+1}^{t}+s_{t+1}=\left(1-\theta p_{t+1}^{C} n_{t+1}\right)(1-\tau) a_{t+1} w_{t+1}, \\
c_{t+2}^{t}=\left(1+r_{t+2}\right) s_{t+1} / p_{t+1}^{A},
\end{gathered}
$$

where $a_{t+1}$ is individual labor productivity, $w_{t}$ the wage rate, $\tau \in(0,1)$ the tax rate, and $s_{t+1}$ saving.

Combining these two equations yields the consolidated budget constraint

$$
c_{t+1}^{t}+\frac{p_{t+1}^{A} c_{t+2}^{t}}{1+r_{t+2}}=\left(1-\theta p_{t+1}^{C} n_{t+1}\right)(1-\tau) a_{t+1} w_{t+1} .
$$

Note that although $\theta$ itself is not a decision variable, it could be made a function of the health status of children. A sick child would normally require more health care, so that $\theta=\theta\left(h_{t+1}^{C}\right)$, with $\theta^{\prime}<0$. This would offer yet another channel through which parental time allocation may affect growth. However, for simplicity, $\theta$ will be kept constant throughout.

\footnotetext{
${ }^{19}$ Note that if death from poor health comes through a painful illness that adults would prefer not to experience, then $p_{t+1}^{A}$ itself could also generate utility.

${ }^{20}$ Alternatively, it could be assumed that rearing costs are incurred for all children, regardless of whether they survive or not. The assumption in the text is more natural, given that in many poor countries mortality in childhood tends to occur early in the life of children.
} 


\section{$3.2 \quad$ Firms}

There is a continuum of identical firms, indexed by $i \in(0,1)$. They produce a single nonstorable good, which is used either for consumption or investment. Production requires the use of private inputs, labor and private capital (which firms rent from the currently old agents), and public capital in infrastructure. ${ }^{21}$ Although public capital is nonexcludable (a firm cannot prevent other firms from using it concomitantly), it is partially rival (use of it by one firm partly precludes its use by another firm) because it is subject to congestion. Specifically, congestion is assumed to be absolute, in the sense that it is directly proportional to the size of the aggregate private capital stock. $^{22}$

Assuming a Cobb-Douglas technology, the production function of firm $i$ takes therefore the form

$$
Y_{t}^{i}=\left(\frac{K_{t}^{I}}{\bar{K}_{t}^{P}}\right)^{\alpha}\left(A_{t} N_{t}^{i}\right)^{\beta}\left(K_{t}^{P, i}\right)^{1-\beta}
$$

where $K_{t}^{P, i}$ denotes the firm-specific stock of capital, $\bar{K}_{t}^{P}=\int_{0}^{1} K_{t}^{P, i}$ the aggregate private capital stock, $K_{t}^{I}$ the stock of public capital in infrastructure, $A_{t}$ average, economy-wide labor productivity (which is the same for all firms), $N_{t}^{i}$ the number of adult workers employed by firm $i$, and $\alpha, \beta \in(0,1)$. Thus, production exhibits constant returns to scale in firm-specific inputs, effective labor $A_{t} N_{t}^{i}$ and capital $K_{t}^{P, i}$.

By contrast, public capital in infrastructure is exogenous to each firm's production process and affects all individual producers in a uniform manner. However, its productivity effects are diminished by excessive use, as measured by the aggregate private capital stock. For instance, the greater the number of trucks operated by the private sector, the greater the likelihood of traffic jams and lost time. The greater the use of electricty-powered machine equipment by individual firms, the higher the pressure on power grids, and the greater the likelihood of power failures. The higher the number of phones operated by the private sector, the greater the risk of calls being dropped. These are particularly important considerations for low-income countries,

\footnotetext{
${ }^{21}$ Firms do not invest in publicly provided services because they cannot internalize their benefits.

${ }^{22}$ See Eicher and Turnovsky (2000) for a detailed discussion of alternative specifications of congestion. In the present case, there is a scale effect, in the sense that congestion increases with the absolute size of the economy.
} 
where public assets in transportation, energy, and telecommunications are, to begin with, limited. For each firm to benefit from $K_{t}^{I}$ as their capital stock increases, public capital must grow at the same rate as the aggregate private capital stock.

Markets for both private capital and labor are competitive. Each firm's objective is to maximize profits, $\Pi_{t}^{i}$, with respect to labor services and private capital, taking as given $K_{t}^{I}$ and $\bar{K}_{t}^{P}$ :

$$
\max _{N_{t}^{i}, K_{t}^{P, i}} \Pi_{t}^{i}=Y_{t}^{i}-r_{t} K_{t}^{P, i}-w_{t} A_{t} N_{t}^{i},
$$

where $r_{t}$ is the rental rate of private capital.

Profit maximization yields

$$
w_{t}=\beta Y_{t}^{i} / A_{t} N_{t}^{i}, \quad r_{t}=(1-\beta) Y_{t}^{i} / K_{t}^{P, i},
$$

which implies that private inputs are paid at their marginal product.

Given that all firms are identical, in a symmetric equilibrium $N_{t}^{i}=N_{t}$ and $K_{t}^{P, i}=K_{t}^{P}=\bar{K}_{t}^{P}, \forall i$. Thus, these conditions become

$$
w_{t}=\beta Y_{t} / A_{t} N_{t}, \quad r_{t}=(1-\beta) Y_{t} / K_{t}^{P} .
$$

Because the number of firms is normalized to 1, aggregate output is given by

$$
Y_{t}=\int_{0}^{1} Y_{t}^{i}=\left(\frac{K_{t}^{I}}{K_{t}^{P}}\right)^{\alpha}\left(\frac{A_{t} N_{t}}{K_{t}^{P}}\right)^{\beta} K_{t}^{P} .
$$

As shown below, in the steady state both the (optimal) public-private capital ratio, $K_{t}^{I} / K_{t}^{P}$, and the (optimal) effective labor-capital ratio, $A_{t} N_{t} / K_{t}^{P}$, are constant. Output $Y_{t}$ is therefore linear in $K_{t}^{P}$. In turn, constant returns to private capital alone result in endogenous growth. A similar result would be obtained if the congestion factor in (5) was assumed to be aggregate output, rather than the aggregate capital stock. ${ }^{23}$

\footnotetext{
${ }^{23}$ Alternative formulations of the production technology to generate endogenous growth would be to specify aggregate output directly as $Y_{t}=\left(K_{t}^{I} A_{t} N_{t}\right)^{\beta}\left(K_{t}^{P}\right)^{1-\beta}$, or $Y_{t}=$ $\left(K_{t}^{I}\right)^{\alpha}\left(A_{t} N_{t}\right)^{\beta}\left(K_{t}^{P}\right)^{1-\alpha-\beta}$. However, although the first specification exhibits constant returns to scale in private capital and effective labor taken together, as well as in private and public capital taken together, it imposes an implausibly large elasticity of output with respect to public capital. The second specification, by contrast, imposes diminishing returns with respect to private inputs; direct payments to capital and labor therefore do not exhaust output, implying non-zero equilibrium profits or implicit rents. This second specification is, in fact, similar to what is obtained here, starting from the assumption of absolute congestion associated with the aggregate private capital stock.
} 
Assuming full depreciation for simplicity, private capital accumulation is driven by

$$
K_{t+1}^{P}=I_{t}
$$

where $I_{t}$ is private investment.

\subsection{Population and Labor Supply}

Let $N_{t}$ be the number of adults at period $t$; the total number of children born at the beginning of that period is thus $n_{t} N_{t}$, so the number of surviving children is $p_{t}^{C} n_{t} N_{t}$. The number of old agents alive in period $t$ is the number of surviving adults from period $t-1$, that is, $N_{t-1} p_{t-1}^{A}$. Thus, total population at the beginning of period $t$ is $\left(1+p_{t}^{C} n_{t}\right) N_{t}+N_{t-1} p_{t-1}^{A}$. Moreover, the number of adults alive in period $t$ is equal to the number of children born in the previous period, $N_{t-1} n_{t-1}$, who survived to period $t$, that is,

$$
N_{t}=p_{t-1}^{C} N_{t-1} n_{t-1}
$$

Total population at the beginning of period $t, L_{t}$, is thus ${ }^{24}$

$$
L_{t}=\left(1+p_{t}^{C} n_{t}\right) p_{t-1}^{C} n_{t-1} N_{t-1}+p_{t-1}^{A} N_{t-1}
$$

\subsection{Health Status and Productivity}

As noted earlier, the health status of children and adults are determined by different factors. The health status of a child, $h_{t}^{C}$, depends on the income spent on goods for each child, the parent's health status, $h_{t}^{A}$, the "effective" amount of time allocated by their parent to rearing them, and access to public services:

$$
h_{t}^{C}=\theta\left(h_{t}^{A}\right)^{\kappa}\left(\zeta_{t} \varepsilon_{t}^{R}\right)^{\nu_{C}}\left(\frac{H_{t}^{G}}{K_{t}^{P}}\right)^{1-\nu_{C}},
$$

where $H_{t}^{G}$ is the supply of public health services (which is also subject to congestion), $\kappa, \nu_{C} \in(0,1)$, and $\zeta_{t}>0$ is an efficiency parameter. First, a child's health status is linear in the share of resources spent on each offspring

\footnotetext{
${ }^{24}$ The ratio of old agents to adults at the beginning of period $t$ is $p_{t-1}^{A} / p_{t-1}^{C} n_{t-1}$, whereas the ratio of children to adults is $n_{t}$. The sum of these two ratios determine the commonly defined dependency ratio, that is, the ratio of old agents and chidren relative to adults. An extension of the analysis would be to assume that this ratio affects the share of government spending on transfers or unproductive outlays.
} 
$\theta$, because it helps to improve their health and their nutrition, thereby reducing their vulnerability to disease (see for instance Pelletier et al. (2003) and Caulfield et al. (2004)). Second, a child's health depends on the parent's health. As noted earlier, this may be related to the impact of parents' physical ability to take care of their children (which may require walking long distances, on difficult terrain, to take them to medical facilities). ${ }^{25}$ Health status at birth, which could be accounted for by adding a linear term $\bar{h}^{C}>0$ in (12), is ignored for tractability.

Third, the health status of a child depends on the degree of efficiency of the time allocated to him by his parent. Specifically, efficiency is assumed to depend on access to infrastructure:

$$
\zeta_{t}=\bar{\zeta}\left(\frac{K_{t}^{I}}{K_{t}^{P}}\right)^{\pi}, \quad \bar{\zeta}>0,
$$

where $\pi \in(0,1)$. In particular, greater access to roads or electricity allows parents to devote less "raw" time to child care, while providing the same effective time. Again, access to infrastructure is assumed subject to congestion, as measured by the private capital stock. ${ }^{26}$

The health status of adults depends (linearly) on their health status in childhood and (with decreasing returns) on the time that they allocate to taking care of their own health:

$$
h_{t+1}^{A}=h_{t}^{C}\left(\varepsilon_{t+1}^{H}\right)^{\nu_{A}}
$$

where $\nu_{A} \in(0,1)$. As before, it could be assumed that infrastructure enhances the time allocated to one's health; this would be captured by multiplying "raw" time by an efficiency factor that depends on access to infrastructure, as in (13). I abstract from this extension, because (13) is sufficient to illustrate the main point of the analysis. ${ }^{27}$

\footnotetext{
${ }^{25}$ If this linkage reflects in utero effects, as also discussed earlier, then instead of $h_{t}^{A}$ it is $h_{t-1}^{A}$ that should appear in (12). If so, however, one would need also to assume that adult health in $t+1$ generates utility directly, to avoid a corner solution with $\varepsilon_{t+1}^{H}=0$. Note also that setting $\kappa=0$ gives results similar to $\kappa<1$.

${ }^{26}$ Alternatively, the congestion factor could be measured in terms of the number of adults in period $t, N_{t}$, or in terms of the total population, $L_{t}$. The specification used here, however, is more tractable analytically. Note also that, given the linearity of aggregate output in $K_{t}^{P}$, using $Y_{t}$ as the congestion factor in (13) and (16) would not alter the results in any fundamental way.

${ }^{27}$ In an initial version of this paper, it was assumed that adult health depends also on acess to public health services. However, the presence of $H_{t+1}^{G} / K_{t+1}^{P}$ in (14) complicates significantly the solution of the model, without adding much insight to the analysis.
} 
Substituting (12), (13), and (A43) in (14) yields

$$
h_{t+1}^{A}=\Phi\left(h_{t}^{A}\right)^{\kappa}\left(\varepsilon_{t}^{R}\right)^{\nu_{C}}\left(\varepsilon_{t+1}^{H}\right)^{\nu_{A}}\left(\frac{K_{t}^{I}}{K_{t}^{P}}\right)^{\nu}\left(\frac{H_{t}^{G}}{K_{t}^{P}}\right)^{1-\nu_{C}},
$$

where $\nu \equiv \pi \nu_{C}$ and $\Phi \equiv \theta \bar{\zeta}^{\nu_{C}}$. Thus, because a parent's health affects his children's health, or equivalently because adult well being depends on own health in childhood, there is serial dependence in $h_{t}^{A}$. In the spirit of Grossman's (1972) approach, health is therefore viewed as a durable stockwhich can be increased here not only by spending more on goods but also by allocating more time to taking care of oneself and one's brood, as well as improvingaccess to public infrastructure and public health services. ${ }^{28}$

Adult productivity is taken to be linear in health status:

$$
a_{t}=h_{t}^{A} .
$$

\subsection{Government}

The government taxes only adults at the constant rate $\tau$ and spends a total of $G_{t}^{I}$ on infrastructure investment, $G_{t}^{H}$ on health, and $G_{t}^{U}$ on other (unproductive) items. ${ }^{29}$ It cannot issue bonds and must therefore run a balanced budget:

$$
G_{t}=G_{t}^{I}+G_{t}^{H}+G_{t}^{U}=N_{t} \tau A_{t} w_{t} .
$$

Shares of spending are constant fractions of revenues:

$$
G_{t}^{h}=v_{h} N_{t} \tau A_{t} w_{t}, \quad h=I, H, U
$$

where $v_{h} \in(0,1)$. Combining (17) and (18) therefore yields

$$
\sum v_{h}=1 .
$$

Public capital depreciates fully at the end of each period. Thus, the law of motion of the public capital stock in infrastructure is given by

$$
K_{t+1}^{I}=G_{t}^{I}
$$

\footnotetext{
${ }^{28}$ See Becker (2007) for a recent overview of Grossman's approach and the subsequent literature. The analysis could be extended to account for the possibility that the stock of health depreciates with age.

${ }^{29}$ The tax rate is assumed to be announced at the beginning of time and the government commits fully and credibly to it; there is therefore no fundamental time-consistency problem, that is, the possibility to renege on fiscal policy announcements.
} 
The production of health services by the government exhibits constant returns to scale with respect to the stock of public capital in infrastructure, $K_{t}^{I}$, and the flow of government spending on health services, $G_{t}^{H}$ :

$$
H_{t}^{G}=\left(K_{t}^{I}\right)^{\mu}\left(\varphi G_{t}^{H}\right)^{1-\mu},
$$

where $\mu, \varphi \in(0,1)$. This specification captures, as discussed earlier, the fact that, in addition to spending on health per se, access to infrastructure is critical to the production of health services in poor countries. Coefficient $\varphi$ is an efficiency parameter that measures the extent to which government spending on health actually helps to produce health services. The proportion $1-\varphi$ measures therefore the fraction of resources "lost" due to poor management or waste - common weakness of health systems in developing countries (see World Health Organization (2000)).

\subsection{Market Clearing and Equilibrium}

Given the assumptions of full depreciation of each stock of capital, and using (9) and (20), the market-clearing condition for the goods market is

$$
Y_{t}=C_{t}+K_{t+1}^{P}+\left(G_{t}^{U}+G_{t}^{H}\right)+K_{t+1}^{I},
$$

where $C_{t}=N_{t}\left[c_{t}^{t}+\theta p_{m}^{C} n_{t}(1-\tau) a_{t} w_{t}\right]+N_{t-1} p_{t-1}^{A} c_{t}^{t-1}$ is total consumption spending at $t$.

The asset market-clearing condition requires tomorrow's private capital stock to be equal to today's aggregate savings by adults:

$$
K_{t+1}^{P}=N_{t} s_{t}
$$

The following definition may therefore be proposed:

Definition 1. A competitive equilibrium for this economy is a sequence of prices $\left\{w_{t}, r_{t}\right\}_{t=0}^{\infty}$, allocations $\left\{c_{t+1}^{t}, c_{t+2}^{t}, s_{t}, \varepsilon_{t+1}^{H}, \varepsilon_{t+1}^{R}\right\}_{t=0}^{\infty}$, public and private capital stocks $\left\{K_{t+1}^{P}, K_{t+1}^{I}\right\}_{t=0}^{\infty}$, health status of children and adults $\left\{h_{t}^{C}, h_{t}^{A}\right\}_{t=0}^{\infty}$, a constant tax rate $\tau$ and constant spending shares $v_{I}, v_{H}$ such that, given the initial capital stocks $K_{0}^{P}$ and $K_{0}^{I}>0$, individuals maximize utility, firms maximize profits, markets clear, and the government budget is balanced.

In equilibrium, individual productivity must also be equal to the economywide average productivity, so that $a_{t}=A_{t}$. The following definition characterizes the balanced growth path: 
Definition 2. A balanced growth equilibrium is a competitive equilibrium in which $c_{t}^{t}, c_{t+1}^{t}, Y_{t} / N_{t}, K_{t}^{P} / N_{t}$, and $K_{t}^{I} / N_{t}$, all grow at the constant endogenous rate $1+\gamma$, and the rate of return on private capital is constant.

Note that this definition does not require health status of children and adults (and thus productivity in middle age as implied by (16)) to be constant in the steady state. Assuming that health status be constant in the long-run equilibrium may seem to be a natural one to make if survival rates are endogenously related to health. However, there are two separate issues here. The first is whether health status should be stationary; the second is whether the survival probability should be as well. Regarding the first, one view is that there are limits in the long run as to how much medical science can improve individual health status. Abstracting from other effects, stationary of health status then implies stationary of the survival rate. Another view is that there are no real limits on the ability of medical research to improve health status - if only marginally, beyond a certain point. According to a recent article in Newsweek (December 15, 2008) for instance, legitimate longevity-boosting treatments could be available in ten years from now. ${ }^{30}$ If so, imposing a strictly concave relationship between health status and the survival rate (akin to a Preston curve) is sufficient to ensure that the survival probability converges to a value lower than unity in the steady state, even though health status itself improves indefinitely. This is implicit in the formulation of Chakraborty (2004) and similar in spirit to Blackburn and Cipriani (2002), where human capital, which grows without bounds, is the main determinant of life expectancy. By implication, there is no good reason to impose stationarity of health status as a requirement for equilibrium, as in Osang and Sarkar (2008) for instance. In fact, I will consider both views in what follows.

To illustrate the functioning of the model, I will first also consider the case where the survival rates are constant at $p_{t+1}^{i}=p_{m}^{i} \forall t$, for $i=C, A$. The impact of health status on the economy is thus solely through productivity in middle age.

\footnotetext{
${ }^{30}$ One can even imagine that some day the technology for transplants will improve sufficiently to allow replacement of any defective organ by using an individual's "own" body components, grown separately.
} 


\section{Time Allocation, Savings, and Life Expectancy}

Each adult maximizes (1) subject to (4), (12), and (14), with respect to $c_{t+1}^{t}$, $c_{t+2}^{t}, \varepsilon_{t+1}^{H}, \varepsilon_{t+1}^{R}$, and $n_{t+1}$, taking $\tau, H_{t}^{G}, \zeta_{t}$ as well as $p_{m}^{C}, p_{m}^{A}$ as given, but taking into account the impact of their decisions regarding $\varepsilon_{t+1}^{R}$ and $\varepsilon_{t+1}^{H}$ on the health status of their children, as well as on their own health status and their productivity.

The solution of the household problem is provided in the Appendix. It shows that in equilibrium, $\varepsilon_{t+1}^{H}, \varepsilon_{t+1}^{R}$, and $n_{t+1}$ are all constant:

$$
\begin{gathered}
\sigma=\frac{p_{m}^{A}}{(1+\rho)+p_{m}^{A}}<1, \\
\tilde{\varepsilon}^{H}=\frac{\eta}{\eta+\Lambda(1+\eta)}<1, \quad p_{m}^{C} \tilde{n} \tilde{\varepsilon}^{R}=\Lambda \tilde{\varepsilon}^{H}<1, \\
\tilde{n}=\frac{\eta_{N}\left(1-\nu_{C}\right)(1-\sigma)}{\theta p_{m}^{C}\left[1+\eta_{N}\left(1-\nu_{C}\right)(1-\sigma)\right]}>0,
\end{gathered}
$$

where $\sigma$ is the marginal propensity to save, $\Lambda \equiv \eta_{N}\left(\nu_{C} / \nu_{A}\right) /\left[\kappa \eta_{N}+(1-\right.$ $\left.\sigma)^{-1}\right]>0$, and $\eta \equiv \eta_{N} \nu_{C} / \eta_{L} \cdot{ }^{31}$ The following assumption must be imposed to ensure that $p_{m}^{C} \tilde{n} \geq 1$, as noted earlier:

Assumption 1: $\theta \leq \eta_{N}\left(1-\nu_{C}\right)(1-\sigma) /\left[1+\eta_{N}\left(1-\nu_{C}\right)(1-\sigma)\right]$.

Thus, the fraction of net income spent on caring for each child cannot be too large.

From solutions (24)-(26), the following proposition can be established:

Proposition 1. An increase in the survival probability from adulthood to old age, $p_{m}^{A}$, increases the savings rate and reduces the fertility rate. It raises the time adults allocate to their own health and lowers total time allocated to surviving children.

The first two results are fairly standard in the recent analytical literature (see, for instance, Blackburn and Cipriani (2002), and Zhang and Zhang (2005)) and consistent with the empirical evidence on longevity and fertility (see for instance Soares (2006) for Brazil). Through a life-cycle effect, a higher adult survival rate dictates a need for higher savings to finance consumption in old age, and thereby has a positive effect, ceteris paribus, on

\footnotetext{
${ }^{31}$ As shown in the Appendix, $\tilde{\varepsilon}^{H}+p_{m}^{C} \tilde{n} \tilde{\varepsilon}^{R}<1$, which implies that the time allocation is feasible and that leisure is positive in equilibrium.
} 
savings in adulthood. Increasing savings involves also reducing rearing costs, and thereby lowers the desired number of children.

In addition, here an increase in the survival rate to old age leads, ceteris paribus, to more time being allocated to taking care of one's health and less time allocated to caring for surviving children. Given that "raw" working time is inelastically supplied, and that health affects productivity, parents also increase their savings by allocating more time to taking care of themselves. This increase in $\tilde{\varepsilon}^{H}$ is met by both a reduction in total time allocated to surviving children's health, $p_{m}^{C} \tilde{n} \tilde{\varepsilon}^{R}$, and by a reduction in leisure, $1-\tilde{\varepsilon}^{H}-p_{m}^{C} \tilde{n} \tilde{\varepsilon}^{R}$. Substitution in time allocation is thus imperfect. ${ }^{32}$ The effect on $\tilde{\varepsilon}^{R}$ itself is in general ambiguous and depends on preferences and the parameters that measure the response of health status in childhood and adulthood to parents' time, $\nu_{C}$ and $\nu_{A}$. In particular, the lower $\nu_{C}$ is, and the higher the ratio $\eta_{N} / \eta_{L}$ is (that is, the higher the relative preference for healthy children compared to leisure), the more likely it is that $d \tilde{\varepsilon}^{R} / d p_{M}^{A}>0$. Intuitively, the reduction in the fertility rate allows parents to allocate more time to each of them to improve their health - even though total time devoted to child rearing falls. In a sense, then, the response reflects a two-level tradeoff: a standard intertemporal trade-off, which involves adults substituting leisure today for consumption tomorrow, and an intratemporal "time allocation" trade-off, which involves substituting rearing time for time allocated to own health and productivity.

From equations (24)-(26), the following proposition can also be established:

Proposition 2. An increase in the survival probability from childhood to adulthood, $p_{m}^{C}$, reduces the fertility rate and has no effect on the savings rate and time allocation.

The fact that the fertility rate is inversely related to the survival probability from childhood to adulthood is consistent with the result established by Kalemli-Ozcan (2003) in a stochastic setting that accounts explicitly for educational choices and ex ante uncertainty about the number of surviving children. In Kalemli-Ozcan's model, parents choose the number of births

\footnotetext{
${ }^{32}$ To establish these results quite simply, note that the solution for $\tilde{\varepsilon}^{R}$ can be written as $p_{m}^{C} \tilde{n} \tilde{\varepsilon}^{R}=\Lambda \tilde{\varepsilon}^{H}$. An increase in $p_{m}^{A}$ lowers $\Lambda$ and raises $\tilde{\varepsilon}^{H}$; however, the former dominates, implying that the overall effect on $\Lambda \tilde{\varepsilon}^{H}$ is negative, which means that $p_{m}^{C} \tilde{n} \tilde{\varepsilon}^{R}$ falls. At the same time, $\tilde{n}$ also falls; given that $p_{m}^{C}$ is constant, the effect on $\tilde{\varepsilon}^{R}$ is thus ambiguous. Note that if $\tilde{\varepsilon}^{R}$ rises, it must do so by less than the fall in in $\tilde{n}$ in absolute terms.
} 
before they know how many children will survive. In a high mortality environment, they increase the number of births beyond the number required to produce the desired number of survivors in expectation. As the mortality rate and thus, uncertainty fall, this precautionary demand decreases. Moreover, lower mortality increases a child's expected lifespan, which encourages parents to invest in the human capital of their offspring. The resources allocated to additional investment in education are freed by the reduction in fertility. Thus, parents find it optimal to move along a quality-quantity frontier, having fewer children and investing more resources in each one.

By contrast, what drives the results summarized in Proposition 1 is the fact that in the present setting parents decide on rearing effort, and material spending per child, after observing child mortality, that is, on the basis of surviving children. In standard fashion, at the optimum each parent equates the (expected and actual) marginal cost of rearing a child with the utility lost in terms of current consumption. By spending more on surviving children, parents reduce current consumption (which entails a utility loss) but also increase their health (which raises utility).

The implication, however, is fundamentally the same. A reduction, say, in the survival probability from childhood to adulthood (or, equivalently, an increase in uncertainty about a child's ability to survive to middle age) generates an "insurance effect," which translates into an increase in the number of (or precautionary demand for) children. This is consistent with the evidence provided by Jeon et al. (2008), who found that an increase in the infant mortality rate (a proxy for a reduction in the child survival rate) tends to raise the fertility rate in Sub-Saharan Africa.

However, there is no effect on the time allocated to child rearing, $p_{m}^{C} \tilde{n} \tilde{\varepsilon}^{R}$; the increase in the survival probability is exactly offset by a reduction in the number of children. In addition, $\tilde{\varepsilon}^{R}$ does not depend on $p_{m}^{C}$ because it is the actual number of children that matters for the allocation of time. This is a consequence of the log-linear utility function chosen here; with a more general specification (as van be inferred from the results of Boucekkine et al. (2008)), it may be possible to show that $p_{m}^{C} \tilde{n} \tilde{\varepsilon}^{R}$ actually increases -implying that there is a quantity-quality trade-off between the number of children and the time allocated to each survivor, as opposed to spending on education, as is Kalemli-Ozcan (2003) and other studies in the tradition of Barro and Becker (1989). ${ }^{33}$

\footnotetext{
${ }^{33}$ Another result worth mentioning is that an increase in rearing costs per child, $\theta$, lowers
} 


\section{Growth and Stagnation}

The balanced growth rate of the economy is derived in the Appendix. Because saving is linear in output and tax revenues are a fraction of income, the public-private capital ratio is given by

$$
k_{t}^{I}=\frac{K_{t}^{I}}{K_{t}^{P}}=\frac{v_{I} \tau}{\sigma(1-\tau)\left(1-\theta p_{m}^{C} \tilde{n}\right)} \equiv J,
$$

where $\theta p_{m}^{C} \tilde{n}<1$ from (26). The term $\sigma(1-\tau)\left(1-\theta p_{m}^{C} \tilde{n}\right)$ can be interpreted as the propensity to save out of after-tax income, net of health outlays.

Using (26) shows that the private-public capital ratio does not depend on the child survival rate. However, it depends indirectly on the adult survival rate, through $\sigma$. As long as the adult survival rate is constant, $\sigma$ is also constant, and the private-public capital ratio remains constant - not only along the balanced growth path but also throughout the adjustment process to any shock. ${ }^{34}$

To further understand the dynamics, consider first the case where $\kappa<1$, that is, the case where a parent's health status exerts a diminishing marginal effect on a child's health. In addition, suppose that $\kappa$ is sufficiently small to ensure that the following (mild) assumption is satisfied:

Assumption 2: $\kappa<1-\beta\left(1-\nu_{C}\right)(1-\mu)$.

Let $x_{t}=K_{t}^{P} / N_{t}$ denote the private capital-raw labor ratio. As shown in the Appendix, the model can now be condensed into an autonomous, firstorder linear difference equation system in $\hat{h}_{t}^{A}=\ln h_{t}^{A}$ and $\hat{x}_{t}=\ln x_{t}$ which can be written as

$$
\left[\begin{array}{l}
\hat{h}_{t+1}^{A} \\
\hat{x}_{t+1}
\end{array}\right]=\left[\begin{array}{l}
a_{10} \\
a_{20}
\end{array}\right]\left[\begin{array}{ll}
a_{11} & a_{12} \\
a_{21} & a_{22}
\end{array}\right]\left[\begin{array}{c}
\hat{h}_{t}^{A} \\
\hat{x}_{t}
\end{array}\right],
$$

where $a_{10}, a_{20}$ are constant terms (defined in the Appendix) and the other coefficients are defined as

$$
a_{11}=\Pi_{2}>0, \quad a_{12}=\Pi_{3}<0,
$$

the fertility rate and increases the time allocated to each surviving child. Thus, there is a quantity-quality trade-off with respect to the number of children and the time allocated to taking care of their health.

${ }^{34}$ Of course, with non-zero depreciation rates, the economy would exhibit transitional dynamics that would involve changes in the public-private capital ratio over time even with a constant saving rate. 


$$
a_{21}=\beta>0, \quad a_{22}=1-\beta>0,
$$

where

$$
\begin{gathered}
\Pi_{2}=\kappa+\beta\left(1-\nu_{C}\right)(1-\mu)>0, \\
\Pi_{3}=-\beta\left(1-\nu_{C}\right)(1-\mu)=\kappa-\Pi_{2}<0,
\end{gathered}
$$

and $\Pi_{2}<1$, as implied by Assumption 2 .

The balanced-growth rate of output per worker is

$$
1+\gamma=\frac{\left(v_{I} \tau\right)^{\alpha}}{p_{m}^{C} \tilde{n}}\left(\tilde{h}^{A}\right)^{\beta} \tilde{x}^{-\beta}\left[\sigma(1-\tau)\left(1-\theta p_{m}^{C} \tilde{n}\right)\right]^{1-\alpha},
$$

where $\tilde{h}$ and $\tilde{x}$ are the steady-state values of $h_{t}^{A}$ and $x_{t}$, which are solutions of the system

$$
\begin{gathered}
\tilde{x}=\left\{\frac{\beta\left(v_{I} \tau\right)^{\alpha}}{p_{m}^{C} \tilde{n}}\left[\sigma(1-\tau)\left(1-\theta p_{m}^{C} \tilde{n}\right)\right]^{1-\alpha}\right\}^{1 / \beta} \tilde{h}^{A}, \\
\tilde{h}^{A}=\left\{\frac{\theta\left(\tilde{\varepsilon}^{R}\right)^{\nu_{C}}\left(\tilde{\varepsilon}^{H}\right)^{\nu_{A}}}{\left(\varphi v_{H} \tau \beta\right)^{-\left(1-\nu_{C}\right)(1-\mu)}} J^{\Pi_{1}}\right\}^{1 /\left(1-\Pi_{2}\right)} \tilde{x}^{\Pi_{3} /\left(1-\Pi_{2}\right)},
\end{gathered}
$$

with

$$
\Pi_{1}=\nu+\left(1-\nu_{C}\right)[\mu+\alpha(1-\mu)]>0 .
$$

Figure 1 illustrates the determination of the steady-state equilibrium. Equation (30) is a straight line with a positive slope depicted as $K K$, whereas equation (31) defines a downward-sloping convex curve depicted as $H H^{35}$ It is immediately clear from the shape of these curves that there is a unique non-trivial equilibrium located at the point at which they intersect, Point $E$. Health status and productivity are thus both constant in the steady state. As shown in the Appendix, the equilibrium is also stable. If the economy is initially at values $\left(h_{0}^{A}, x_{0}\right)$ corresponding to, say, Point $A$, it will converge monotonically to $E$. However, at initial values corresponding to Point $B$, the economy may cycle around the equilibrium point.

Equations (29) and (31) can be used to perform a variety of experiments, which can be illustrated graphically. In particular, an increase in the share

\footnotetext{
${ }^{35}$ If productivity is not linear in adult health status, but exhibits instead decreasing marginal returns, so that (16) is replaced by an equation such as $a_{t}=\left(h_{t}^{A}\right)^{\chi}$, where $\chi \in(0,1), \tilde{h}^{A}$ in equation (30) would be replaced by $\left(\tilde{h}^{A}\right)^{\chi}$, and curve $K K$ in Figure 1 would have a positive and concave slope.
} 
of government spending on health, $v_{H}$, financed by a cut in unproductive expenditure, shifts $H H$ upward while leaving $K K$ constant; the outcome is both an improvement in health status and a higher capital-labor ratio.

More importantly for the purpose at hand, it can be verified that substituting (A37) in (A36) implies that $\gamma=0$; thus, output per worker is constant in the steady state. ${ }^{36}$ Intuitively, if $h^{A}$ is constant, so must be $x$; this implies that the stock of private capital (and thus the level of output, given (A24)) must grow at the same rate as the rate of growth of the adult populationand so does the stock of public capital, given that $J$ is constant. If $J, h^{A}$, and $x$ are all constant so must be output per worker, as implied by (A35). This can be summarized in the following Proposition:

Proposition 3. If parents' health status exerts a diminishing marginal effect on a child's health, the model possesses only one equilibrium, which is stable and characterized by a zero steady-state growth rate in income per worker, that is, a pure stagnation equilibrium (PSE).

Note that the existence of a PSE depends only partly on the assumption of proportional congestion in output and the supply of health services; even if $k_{t}^{I}$ in (27) was assumed to be time-varying, a PPT would still emerge. What Proposition 3 does depend on is the fact that the capital-labor ratio is defined in terms of raw labor. If the model were to account also for human capital accumulation, the capital-labor ratio would accordingly be defined in terms of efficiency units of labor; as long as the human capital stock can grow without bound, a PSE would not emerge. However, even then the economy may still exhibit low growth and poor health outcomes.

In addition to unique equilibria with zero growth, the model may also generate multiple development regimes and poverty traps. In the next section, I examine how full persistence in health may lead to such outcomes. I also explore the role of public policy in that context.

\section{Persistence in Health and Public Policy}

Consider now the case where $\kappa=1$, that is, a parent's health status has a linear effect on a child's health. As can be inferred from (15), this implies a

\footnotetext{
${ }^{36}$ Note that from (10) $L_{t+1}=\left(1+p_{m}^{C} \tilde{n}\right) p_{m}^{C} \tilde{n} N_{t}+p_{m}^{A} N_{t}$, or equivalently, using (11), $L_{t+1}=\left[\left(1+p_{m}^{C} \tilde{n}\right) p_{m}^{C} \tilde{n}+p_{m}^{A}\right]\left(p_{m}^{C} \tilde{n}\right)^{-1} N_{t+1}$; thus, total population is proportional to the number of adult workers. This implies that $L_{t+1} / L_{t}=N_{t+1} / N_{t}$, so that the growth rate of aggregate output per capita is also zero.
} 
unit root in adult health status.

As shown in the Appendix, with $\kappa=1$ the system boils down to an autonomous first-order linear difference equation in $\hat{q}_{t}=\ln q_{t}=\ln \left(h_{t}^{A} / x_{t}\right)$, where $q_{t}$ is the effective labor-capital ratio:

$$
\hat{q}_{t+1}=\ln \Pi+\Omega_{2} \hat{q}_{t}
$$

with

$$
\begin{gathered}
\Omega_{2} \equiv 1-\beta\left[1-\beta\left(1-\nu_{C}\right)(1-\mu)\right]>0, \\
\Pi=\frac{\theta\left(\tilde{\varepsilon}^{R}\right)^{\nu_{C}}\left(\tilde{\varepsilon}^{H}\right)^{\nu_{A}} J^{\Omega_{1}-\alpha}}{\left(\varphi v_{H} \tau \beta\right)^{-\left(1-\nu_{C}\right)(1-\mu)}}\left\{\frac{\beta \sigma(1-\tau)\left(1-\theta p_{m}^{C} \tilde{n}\right)}{p_{m}^{C} \tilde{n}}\right\}^{-1}, \\
\Omega_{1} \equiv \pi \nu_{C}+\left(1-\nu_{A}\right)[\mu+\alpha(1-\mu)]>0,
\end{gathered}
$$

and $\Omega_{1}-\alpha>0$. Stability of this equation requires $\Omega_{2}<1$; this condition is always satisfied. Thus, given (strict) concavity, there is a unique, nontrivial and globally stable steady state $\tilde{q}$, to which $q_{t}$ converges monotonically:

$$
\tilde{q}=\Pi^{1 /\left(1-\Omega_{2}\right)} .
$$

The balanced growth rate (in per capita terms) is now given by

$$
1+\gamma=\frac{\left(v_{I} \tau\right)^{\alpha}}{p_{m}^{C} \tilde{n}} \tilde{q}^{\beta}\left[\sigma(1-\tau)\left(1-\theta p_{m}^{C} \tilde{n}\right)\right]^{1-\alpha},
$$

Because $q_{t}$ is constant in the steady state, adult health status $h_{t}^{A}$ and the capital-labor ratio $x_{t}$ grow at the same constant rate. The growth rate of $x_{t}$ is the same as the growth rate of output per worker, and so therefore is the growth rate of $h_{t}^{A}$. The growth rate of public capital per worker is also equal to the growth rate of output per worker; and from (27), given that the public-private capital ratio is constant throughout, the stock of private capital per worker also grows at the same rate.

Equations (25) to (35) can now be used to examine the impact of a variety of parameters and policy variables on long-run growth. In particular, the following result can be established:

Proposition 4. An increase in the survival rate from childhood to adulthood has no effect on the growth rate of output per worker, whereas an increase in the survival rate from adulthood to old age has an ambiguous effect.

The reason why an increase in $p_{m}^{C}$ has no effect on the growth rate (measured either in absolute terms or per worker) is that its direct effect is offset 
by an exact opposite effect on the fertility rate, which as noted earlier leaves the product $p_{m}^{C} \tilde{n}$ intact (see (26) and (34)). ${ }^{37}$ By contrast, an increase in $p_{m}^{A}$ affects growth essentially through an increase in the savings rate, $\sigma$; as noted earlier, with higher likelihood to surviving to old age, adults save more for late-life consumption. In turn, changes in $\sigma$ affect growth both directly, and indirectly, through changes in the steady-state values of the effective laborprivate capital ratio and the fertility rate. The direct effect is positive - a higher savings rate raises the rate of private capital accumulation. The indirect effect through fertility is also unambiguously positive. The indirect effect on $\tilde{q}$ operates, as can be inferred from (33), and (34), through changes in time allocation, fertility, and the public-private capital ratio. An increase in $p_{m}^{A}$, by proposition 1 , raises $\tilde{\varepsilon}^{H}$ but reduces $\tilde{n}$ and possibly $\tilde{\varepsilon}^{R}$. The reduction in the fertility rate unambiguously raises the growth rate per worker, by reducing the number of adults and reducing the share of income allocated to child care. However, changes in time allocation may go in opposite directions. Moreover, as can be inferred from (27), an increase in the savings rate always lowers the public-private capital ratio, implying that $J$ falls. This effect would occur even if infrastructure exerted no externality effects on the efficiency of time allocated to child rearing and the production of health services $(\pi=\mu=0)$, as long as $\alpha>0$. Given these conflicting effects on the effective labor-private capital ratio, the net effect on the steady-state growth rate, $d(1+\gamma) / d p_{m}^{A}$, cannot be determined a priori.

This result is illustrated in Figure 2. The vertical curve $Q Q$ corresponds to (34), whereas the concave curve $G G$ corresponds to (35). The initial steady state obtains at $E$. An increase in $p_{m}^{A}$ shifts $G G$ upward, whereas $Q Q$ may shift either left or right. The steady-state growth rate per worker increases at points $B$ and $C$, but falls at Point $A$.Thus, the analysis shows that the "standard" view, according to which an increase in the adult survival rate promotes growth (as for instance in Blackburn and Cipriani (2002) and Zhang and Zhang (2005)), does not necessarily hold when the allocation of time is modeled with greater complexity. ${ }^{38}$

\footnotetext{
${ }^{37}$ This result is in contrast to Ehrlich and Lui (1991), who showed in a three-period OLG model with human capital accumulation that both survival rates in childhood and adulthood affect growth. The key reason for the difference is their assumption that parents and children engage in implicit contracts. The family is thus an informal, jointly breneficial insurance mechanism, which links generations through internal transfers.

${ }^{38}$ In Blackburn and Cipriani (2002) for instance, an increase in the (adult) survival rate raises the opportunity costs of current work and reproduction by raising the future returns
} 
At a low level of life expectancy, it is again possible for the economy to generate a stagnation equilibrium, this time characterized by a low level of growth in income per worker and high fertility. In addition, the following result can be established:

Proposition 5. The lower the share of government spending allocated to health, $v_{H}$, or the lower the efficiency of that category of spending, as measured by $\varphi$, the lower the equilibrium growth rate of output per worker.

As noted earlier, the low efficiency of public outlays on health in developing countries is well documented. However, its implications for long-run growth have not been clearly spelt out in previous work. What is clear now from Proposition 5 is that it may be a key source of stagnation, even if the level of spending itself is high. ${ }^{39}$ If so then, governance reforms are essential to spur growth. Put differently, increasing the resources allocated to health systems may be important to improving health and growth outcomes in poor countries, but even more important in some countries may be the need to use existing resources more efficiently.

A related issue that is well illustrated by these results is that although spending on infrastructure and health are complementary in terms of their impact on the production of health services, they may be substitutes (depending on how productive spending is financed) in terms of their impact on growth. If an increase, say, in the share of spending on health is financed by a cut in unproductive expenditure $\left(d v_{H}=-d v_{U}\right)$, then it unambiguously raises the balanced growth rate through an indirect effect on $\tilde{q}$. However, if it is financed by a cut in investment in infrastructure $\left(d v_{H}=-d v_{I}\right)$, it will have ambiguous effects. Whether the net effect is positive or negative depends of course on the technology parameters characterizing both the production of goods and health services, as documented in various other studies (see Agénor (2008) and Agénor and Neanidis (2006)). In addition, in the present setting it also depends on the degree of efficiency of health spending (as noted earlier) and the efficiency effect of infrastructure on the time allocated to child rearing (as captured by $\pi$ ). This can be summarized in the following proposition:

to human capital accumulation. Under such circumstances, agents devote more of their time to education and have fewer numbers of children when young, implying a higher growth rate of output.

${ }^{39} \mathrm{~A}$ similar result can be established regarding the efficiency of public investment in infrastructure; see Agénor (2006). 
Proposition 6. An increase in the share of government spending on health, financed by a cut in the share of investment in infrastructure, has in general an ambiguous effect on the balanced growth rate. All else equal, the lower the efficiency of health spending, and the greater the efficiency effect of infrastructure on the time allocated to child rearing, the greater the likelihood that the net effect will be negative.

\section{Threshold Effects}

The foregoing analysis focused on the case of a constant survival rate and a unique balanced growth equilibrium. I now examine the case where survival is endogenously related to health outcomes and examine whether multiple development regimes can emerge. I also study the role of public policy in that context.

A natural route to follow in the present setting would be to consider the case where survival rates in both childhood and adulthood are related (possibly in a nonlinear fashion) to the individual's own health status. In solving their optimization problem, parents would then internalize the implications of their time allocation decisions. Unfortunately, given the complexity of the model, endogenizing both probabilities in this way precludes an analytical treatment, and numerical methods must be used.

Alternatively, suppose that survival probabilities of any particular individual depends on average health status in the economy - which, in equilibrium, is of course the same for all individuals. For instance, if you stop smoking, but you continue to be surrounded by smokers, your health prospects will not necessarily improve. If you quit drinking, but nobody else does, the risk of you getting involved in a car accident involving a drunk driver will not necessarily diminish. In an environment where deadly communicable diseases can spread rapidly (as is often the case in urban slums in developing countries), and vaccines do not completely protect from the risk of getting infected, one individual getting immunized will not change the risk to which he is exposed (and therefore his survival probability), unless all individuals get immunized; and so on.

In such conditions, it is natural to retain the assumption that agents do not internalize the effect of their time allocation decisions on their own survival probability. To further simplify, I will also assume that the survival rate in childhood remains constant at $p_{m}^{C}$ and focus on the endogenous deter- 
mination of the adult survival rate. This is a sensible way to proceed in the present setting because health status in childhood is fundamentally a function of the health status of parents, and (as shown earlier) long-run growth in output per worker does not depend on the survival rate of children.

Suppose then that the adult survival rate is now a piece-wise function defined as

$$
p_{t}^{A}= \begin{cases}p_{m}^{A} & \text { If } h_{t}^{A} \leq h_{m}^{A} \\ p_{M}^{A} & \text { If } h_{t}^{A}>h_{m}^{A}\end{cases}
$$

where $p_{m}^{A}, p_{M}^{A} \in(0,1)$. Thus, if health status is below $h_{m}^{A}$, the likelihood of surviving into old age is $p_{m}^{A}$, as before. As health status improves above that threshold, the survival probability increases to $p_{M}^{A}>p_{m}^{A}$ and remains insensitive to further changes in health outcomes.

The model may now display multiple development regimes, as illustrated in Figure 3. The left-hand panel displays (32), in level form, whereas the right-hand panel displays curve $G G$, as in Figure 2. For $h_{0}^{A} \leq h_{m}^{A}$, or equivalently for $q_{0}=h_{0}^{A} / x_{0} \leq q_{m}=h_{m}^{A} / x_{0}$, the economy will converge to the low-growth equilibrium point $A$, with growth at $A^{\prime}$. If the net effect of an increase in the survival rate on $q_{t}$ is positive, once the economy crosses $q_{m}$, it will converge to the high-growth equilibrium point $B ; G G$ shifts to the left, and the steady-state growth is obtained at $B^{\prime}$. The stagnating equilibrium is thus characterized also by poor health outcomes for both parents and children. However, if the net effect of an increase in the survival rate on $q_{t}$ is negative, the economy may converge to an even lower equilibrium rate than point $A$, such as the one characterized by points $C$ and $C^{\prime}$. Note also that even though the steady-state value of $q_{t}$ is now lower, this does not necessarily imply a lower growth rate; If $G G$ shifts sufficiently to the left, the long-run growth rate may actually go up, because the direct effect of the increase in the survival rate on the savings rate and fertility dominates. This is the case illustrated at Point $C^{\prime \prime}$.

What is the role of policy then? As noted earlier, a shift from unproductive spending toward health outlays may increase health status sufficiently to ensure that over time $h_{t}^{A}$ exceeds $h_{m}^{A}$, and thereby put the economy on a new (higher) growth trajectory. At the same time, however, if the degree of efficiency of health outlays is low, or if the increase in health spending is financed by a cut in productive spending, a better strategy may actually be a Big Push in public investment in infrastructure - provided of course that such spending is itself sufficiently efficient. Put differently, given the com- 
plementarity between public capital in infrastructure and other inputs in the production of health services, the best way to improve health outcomes may not be to increase health spending per se-a dimension that is often forgotten in the debate on improving health indicators in poor countries. In general, the model suggests that a two-pronged strategy, involving spending on both health and infrastructure (given diminishing returns to each production input), accompanied by governance reform aimed at improving spending efficiency, stands the best chance of helping a country to escape from a low-growth poverty trap of the type identified in this paper.

Consider now the more general case where $p_{t}^{A}$ varies over time as a function of health status, so that $p_{t}^{A}=f\left(h_{t}^{A}\right)$. Suppose also that the function satisfies $f\left(h_{t}^{A}\right)=p_{m}^{A}$ for $h_{t}^{A} \leq h_{1}^{A}, f^{\prime}>0, f^{\prime \prime}>0$ for $h_{1}^{A}<h_{t}^{A}<h_{2}^{A}$ and $f^{\prime}>0, f^{\prime \prime}<0$ for $h_{t}^{A}>h_{2}^{A}$, and $\lim _{h_{t}^{A} \rightarrow \infty} f(\cdot)=p_{M}^{A}<1$. Thus, the survival rate has a convex-concave shape, as shown in Figure 4. At low initial levels of health status, improvements in health generate strong increases in the survival rate; beyond a certain point, improvements in health generate decreasing marginal returns. As health status goes to infinity, the survival rate converges to $p_{M}^{A}>p_{m}^{A}$. This accords well with the evidence for low-income countries. $^{40}$

With $p_{t}^{A}$ endogenous, all adult decision rules (24)-(26) derived earlier continue to apply as is, except that now the optimal values become time dependent. In addition, the public-private capital ratio given in (27) is no longer constant. The model therefore cannot be solved for explicitly and numerical simulations become necessary to calculate and trace the path of the different variables, establish convergence, and examine the impact of shifts in policy instruments. Nevertheless, it is intuitively clear that the model can now generate a wide range of steady-state equilibria, some of them again characterized by low growth and poor health outcomes.

\footnotetext{
${ }^{40} \mathrm{~A}$ function that satisfies the properties illustrated in the figure for $h_{t}^{A}>h_{m}^{A}$ is the generalized logistic curve,

$$
p_{t}^{A}=\frac{p_{m}^{A}[1+\exp (\omega b)]-p_{M}^{A}\left[1-\exp \left\{\zeta\left(h_{t}^{A}-h_{m}^{A}\right\}\right]\right.}{\exp (\omega b)+\exp \left\{\zeta\left(h_{t}^{A}-h_{m}^{A}\right)\right\}},
$$

where $b$ is a parameter that determines the turning point of the function, $\omega$ a parameter that determines the speed of transition, $\zeta \in(0,1)$. Strictly concave functional forms are discussed in Blackburn and Cipriani (2002), Hashimoto and Tabata (2005), Chakraborty (2004), and Tang and Zhang (2007).
} 


\section{Concluding Remarks}

The purpose of this paper was to present a three-period OLG model that combines three important issues in the determination of long-run growth in poor countries: interactions between public capital in infrastructure and health outcomes; the dependence of health in adulthood on health in childhood; and the implications of infrastructure for the allocation of time. The first part of the paper provided an informal review of the evidence on these issues. In particular, it was noted that access to infrastructure is critical to the production of health services in poor countries. To function properly, hospitals need access to electricity. With inadequate water, sanitation and waste disposal facilities, medical facilities cannot provide the services that are expected from them. In addition, it was noted that by reducing the time allocated by households to collecting water and wood, greater access to infrastructure may lead to an increase in the time available for child care activities (such as teaching children and looking after their hygiene and nutrition needs) and for own health care. Unlike most of the existing literature, both of these activites are treated as productive.

The second part of the paper described the model. In line with the previous discussion, infrastructure in the model affects not only the production of goods but also the production of health services and the efficiency of parents' time spent on children. At the beginning of the first period of life and the end of the second, there is a non-zero probability of dying. Health status in adulthood depends on the effective time spent caring about one's health and health status in childhood. There is therefore "serial dependence" in health outcomes. Crucially, what matters for parents is not how many children they have per se but rather the number of healthy surviving children.

The third part characterized optimal household decisions and examined the impact of life expectancy. A key property of the model is that agents fully internalize the implications of changes in child survival rate on their fertility decisions; this implies that changes in that rate have no effect on longrun growth. The fourth part showed that with partial persistence in health (which implies stationarity in health status), the economy's equilibrium is a pure poverty trap, characterized by zero growth in income per worker. The fifth part showed that if adult health status can improve indefinitely, a stagnating equilibrium with low growth, poor health outcomes, and high fertility may also result from inadequate access to infrastructure. Moreover, in contrast to the existing literature, an autonomous increase in the adult 
survival rate is shown to have an ambiguous effect on growth, because of indirect effects on capital accumulation and time allocation. This result helps to explain why empirical studies may have had difficulty establishing a robust impact of life expectancy on growth and standards of living (see Finlay (2007) and Ashraf, Lester, and Weil (2008)). Another implication of the analysis is that the common assumption in OLG models that time allocated to children's care is time taken away from market work, and is therefore "unproductive," is not warranted. If time allocated to child care helps to improve children's health status, it will determine their productivity and earning capacity in adulthood, and may therefore have a substantial impact on growth.

The last part of the paper partially endogenized the adult survival probability by relating it through threshold effects to health status. Multiple steady-state growth rates were shown to be possible, implying that the limiting outcomes of the economy depend critically on initial conditions. The role of public policy in that context was also examined; it was shown that getting health outcomes to improve beyond the critical level necessary to ensure convergence to a high-growth path may involve increasing public investment in infrastructure, rather than raising spending on health per se.

The analysis can be extended in various directions. First, the model can be used to examine growth- and welfare-maximizing public spending policies. The key trade-off embedded in the model is that while public health spending may increase longevity, and therefore saving, investment in physical capital, and growth, it may also reduce growth if it occurs at the expense of other components of productive spending. ${ }^{41}$ This is because the provision of each category of public services requires committing resources, the level of which is constrained by available tax revenues. Less investment in infrastructure, in particular, would not only curtail the benefits associated with public capital in the production of goods and health services, but it could also force parents to allocate more time to market activity (to compensate for an adverse effect on wages) and less time to child rearing. In turn, this would affect children's health in adulthood and therefore worker productivity and growth. While the issue of spending allocation was mentioned earlier, a more thorough analysis would be warranted.

\footnotetext{
${ }^{41}$ Osang and Sarkar (2008) discuss a similar trade-off in terms of education and health spending. However, in their model health status is independent of time, and therefor they do not explore the implications of their analysis for the allocation of time, growth, and welfare.
} 
A second extension is to account for interactions between education and health, as well as infrastructure and education. As documented in a number of studies, health is an important factor in determining the quantity and quality of human capital. As discussed in more detail by Galor and Mayer-Foulkes (2004) for instance, improving the health of individuals also increases the effectiveness of education. In turn, increasing education levelsabove and beyond their effect on income - can also improve health outcomes. In this context the gender dimension may be important. As pointed out by Kohler and Soldo (2004), in practice, there are two potential channels that may relate parent's education to children's health and offsprings' late-life health outcomes: if it is the father's education that is a stronger predictor of the child's health, then this may indicate that education operates through economic circumstances (because fathers may be those who were the primary suppliers of economic resources in the family). If, in contrast, health status is determined to a large extent by the mother's education, then this may suggest that education determines health through knowledge about health care and health behavior that are essential determinants of children's health outcomes. This is also consistent with the evidence suggesting that an increase in female education reduces infant mortality and raises the survival rate for children, even after controlling for income effects (see Wagstaff and Claeson (2004)). At the same time, infrastructure may have important effects on education outcomes. Empirical studies have shown for instance that children in households with access to electricity have higher education levels than those without, whereas access to roads can make positions in rural schools more attractive to teachers. Agénor and Agénor (2009) explore some of these issues in an OLG model that also accounts for gender bias in mothers' time allocation between their sons and daughthers. 


\section{Technical Appendix}

Before solving the individual's maximization problem, note that in equation (15), which can be rewritten here (with $\Phi=1$ ) for convenience:

$$
h_{t+1}^{A}=a_{t+1}=\left(h_{t}^{A}\right)^{\kappa}\left(\varepsilon_{t}^{R}\right)^{\nu_{C}}\left(\varepsilon_{t+1}^{H}\right)^{\nu_{A}}\left(\frac{K_{t}^{I}}{K_{t}^{P}}\right)^{\nu}\left(\frac{H_{t}^{G}}{K_{t}^{P}}\right)^{1-\nu_{C}},
$$

where $a_{t}$ and $\varepsilon_{t}^{R}$ are predetermined from the point of view of decisions taken at the beginning of period $t+1$.

Writing equations (12) for $t+1$, as well as (14), yields

$$
\begin{gathered}
h_{t+1}^{C}=\theta\left(h_{t+1}^{A}\right)^{\kappa}\left(\zeta_{t+1} \varepsilon_{t+1}^{R}\right)^{\nu_{C}}\left(\frac{H_{t+1}^{G}}{K_{t+1}^{P}}\right)^{1-\nu_{C}}, \\
h_{t+1}^{A}=h_{t}^{C}\left(\varepsilon_{t+1}^{H}\right)^{\nu_{A}},
\end{gathered}
$$

which can be combined to give

$$
h_{t+1}^{C}=\theta\left(h_{t}^{C}\right)^{\kappa}\left(\varepsilon_{t+1}^{H}\right)^{\kappa \nu_{A}}\left(\zeta_{t+1} \varepsilon_{t+1}^{R}\right)^{\nu_{C}}\left(\frac{H_{t}^{G}}{K_{t}^{P}}\right)^{1-\nu_{C}} .
$$

Consider first the case where $p_{t+1}^{C}=p_{m}^{C}$ and $p_{t+1}^{A}=p_{m}^{A}$. From (1), each individual therefore maximizes

$$
\begin{gathered}
U=\ln c_{t+1}^{t}+\eta_{L} \ln \left(1-\varepsilon_{t+1}^{H}-p_{m}^{C} n_{t+1} \varepsilon_{t+1}^{R}\right) \\
+\eta_{N} \ln p_{m}^{C} h_{t+1}^{C} n_{t+1}+p_{m}^{A} \frac{\ln c_{t+2}^{t}}{1+\rho}
\end{gathered}
$$

with respect to $c_{t+1}^{t}, c_{t+2}^{t}, \varepsilon_{t+1}^{H}, \varepsilon_{t+1}^{R}$, and $n_{t+1}$, subject to (A1), (A2), as well as (4), which is rewritten here for convenience:

$$
\left(1-\theta p_{m}^{C} n_{t+1}\right)(1-\tau) a_{t+1} w_{t+1}-c_{t+1}^{t}-\frac{p_{m}^{A} c_{t+2}^{t}}{1+r_{t+2}}=0 .
$$

First-order conditions yield the familiar Euler equation

$$
\frac{c_{t+2}^{t}}{c_{t+1}^{t}}=\frac{1+r_{t+2}}{1+\rho}
$$


together with

$$
\begin{gathered}
-\frac{\eta_{L}}{1-\varepsilon_{t+1}^{H}-p_{m}^{C} n_{t+1} \varepsilon_{t+1}^{R}}+\frac{\eta_{N} \kappa \nu_{A}}{\varepsilon_{t+1}^{H}}=-\frac{(1-\tau)\left(1-\theta p_{m}^{C} n_{t+1}\right) \nu_{A} a_{t+1} w_{t+1}}{c_{t+1}^{t} \varepsilon_{t+1}^{H}} \\
-\frac{\eta_{L} p_{m}^{C} n_{t+1}}{1-\varepsilon_{t+1}^{H}-p_{m}^{C} n_{t+1} \varepsilon_{t+1}^{R}}+\frac{\eta_{N} \nu_{C}}{\varepsilon_{t+1}^{R}}=0 \\
-\frac{\eta_{L} p_{m}^{C} \varepsilon_{t+1}^{R}}{1-\varepsilon_{t+1}^{H}-p_{m}^{C} n_{t+1} \varepsilon_{t+1}^{R}}+\frac{\eta_{N}}{n_{t+1}}=\frac{\theta p_{m}^{C}(1-\tau) a_{t+1} w_{t+1}}{c_{t+1}^{t}}
\end{gathered}
$$

Substituting (A5) in the intertemporal budget constraint (A4) yields

$$
c_{t+1}^{t}=\left[\frac{1+\rho}{(1+\rho)+p_{m}^{A}}\right](1-\tau)\left(1-\theta p_{m}^{C} n_{t+1}\right) a_{t+1} w_{t+1},
$$

so that saving, $s_{t+1}=(1-\tau)\left(1-\theta p_{m}^{C} n_{t+1}\right) a_{t+1} w_{t+1}-c_{t+1}^{t}$, is equal to

$$
s_{t+1}=\sigma(1-\tau)\left(1-\theta p_{m}^{C} n_{t+1}\right) a_{t+1} w_{t+1}, \quad \sigma \equiv \frac{p_{m}^{A}}{(1+\rho)+p_{m}^{A}}<1 .
$$

Substituting (A9) in (A6) and (A8) yields

$$
\begin{gathered}
\frac{\eta_{L}}{1-\varepsilon_{t+1}^{H}-p_{m}^{C} n_{t+1} \varepsilon_{t+1}^{R}}=\frac{\nu_{A}}{\varepsilon_{t+1}^{H}}\left[\kappa \eta_{N}+\left(\frac{1}{1-\sigma}\right)\right], \\
\frac{\eta_{L} p_{m}^{C} \varepsilon_{t+1}^{R}}{1-\varepsilon_{t+1}^{H}-p_{m}^{C} n_{t+1} \varepsilon_{t+1}^{R}}-\frac{\eta_{N}}{n_{t+1}}=-\frac{\theta p_{m}^{C}}{(1-\sigma)\left(1-\theta p_{m}^{C} n_{t+1}\right)} .
\end{gathered}
$$

Dividing equation (A7) by (A11) yields

$$
p_{m}^{C} n_{t+1}=\frac{\eta_{N} \nu_{C} \varepsilon_{t+1}^{H}}{\nu_{A} \varepsilon_{t+1}^{R}}\left[\kappa \eta_{N}+\left(\frac{1}{1-\sigma}\right)\right]^{-1},
$$

so that

$$
p_{m}^{C} n_{t+1} \varepsilon_{t+1}^{R}=\Lambda \varepsilon_{t+1}^{H},
$$

where

$$
\Lambda \equiv \eta_{N}\left(\frac{\nu_{C}}{\nu_{A}}\right)\left[\kappa \eta_{N}+\left(\frac{1}{1-\sigma}\right)\right]^{-1}>0 .
$$

Equation (A7) can be rewritten as

$$
\frac{p_{m}^{C} n_{t+1} \varepsilon_{t+1}^{R}}{1-\varepsilon_{t+1}^{H}-p_{m}^{C} n_{t+1} \varepsilon_{t+1}^{R}}=\frac{\eta_{N} \nu_{C}}{\eta_{L}} .
$$


Substituting (A13) back in this expression yields

$$
\frac{\Lambda \varepsilon_{t+1}^{H}}{1-(1+\Lambda) \varepsilon_{t+1}^{H}}=\eta
$$

where $\eta \equiv \eta_{N} \nu_{C} / \eta_{L}$.

This equation can be solved for the optimal value of $\varepsilon_{t+1}^{H}$ :

$$
\tilde{\varepsilon}^{H}=\frac{\eta}{\eta+\Lambda(1+\eta)}<1 .
$$

This result implies that $\tilde{\varepsilon}^{H}=0$ if either $\eta_{N}=0$ (bearing children brings no utility) or $\nu_{C}=0$ (time spent in child rearing does not affect a child's health status). The reason is that in the model adult health is not valued per se, but only to the extent that it benefits children.

Substituting (A13) in (A12) yields

$$
\frac{\eta_{L} \Lambda \tilde{\varepsilon}^{H}}{n_{t+1}\left[1-(1+\Lambda) \tilde{\varepsilon}^{H}\right]}-\frac{\eta_{N}}{n_{t+1}}=-\frac{\theta p_{m}^{C}}{(1-\sigma)\left(1-\theta p_{m}^{C} n_{t+1}\right)} .
$$

Using (A15), this equation gives

$$
\frac{\eta_{L} \eta-\eta_{N}}{n_{t+1}}=-\frac{\theta p_{m}^{C}}{(1-\sigma)\left(1-\theta p_{m}^{C} n_{t+1}\right)},
$$

which, noting that $\eta_{L} \eta-\eta_{N}=-\eta_{N}\left(1-\nu_{C}\right)$, can be solved for $n_{t+1}$ :

$$
\tilde{n}=\frac{\eta_{N}\left(1-\nu_{C}\right)(1-\sigma)}{\theta p_{m}^{C}\left[1+\eta_{N}\left(1-\nu_{C}\right)(1-\sigma)\right]}>0 .
$$

Combining (A13) and (A17) yields

$$
\tilde{\varepsilon}^{R}=\Lambda\left(\frac{\tilde{\varepsilon}^{H}}{p_{m}^{C} \tilde{n}}\right)=\Lambda \frac{\theta\left[1+\eta_{N}\left(1-\nu_{C}\right)(1-\sigma)\right]}{\eta_{N}\left(1-\nu_{C}\right)(1-\sigma)} \tilde{\varepsilon}^{H},
$$

which shows that $\tilde{\varepsilon}^{R}=0$ if $\tilde{\varepsilon}^{H}=0$ and that $\tilde{\varepsilon}^{R}$ does not depend on $p_{m}^{C}$. From (A16), (A17), and (A18), it can also be shown that $\tilde{\varepsilon}^{H}+p_{m}^{C} \tilde{n}_{\tilde{\varepsilon}}^{R}<1$. Indeed, from (A18), $p_{m}^{C} \tilde{n} \tilde{\varepsilon}^{R}=\Lambda \tilde{\varepsilon}^{H}$; then $\tilde{\varepsilon}^{H}+p_{m}^{C} \tilde{\varepsilon} \tilde{\varepsilon}^{R}=(1+\Lambda) \tilde{\varepsilon}^{H}$. For the left-hand side to be less than one requires $\tilde{\varepsilon}^{H}<1 /(1+\Lambda)$. Combined with (A16), this condition boils down to $\Lambda>0$, which is always satisfied (see (A14)). 
Thus, leisure is positive in equilibrium. By implication, it is also true that $p_{m}^{C} \tilde{n} \tilde{\varepsilon}^{R}<1$. From (A17), $1-\theta p_{m}^{C} \tilde{n}>0$.

A higher $p_{m}^{A}$ raises the propensity to save (from (A10)). From (A14), it lowers $\Lambda$; using (A16) and (A18) it can be shown that

$$
\begin{gathered}
\frac{d \tilde{\varepsilon}^{H}}{d p_{m}^{A}}>0, \quad \frac{d\left(p_{m}^{C} \tilde{n} \tilde{\varepsilon}^{R}\right)}{d p_{m}^{A}}=\frac{d\left(\Lambda \tilde{\varepsilon}^{H}\right)}{d p_{m}^{A}}<0, \\
\frac{d \tilde{n}}{d p_{m}^{A}}<0, \quad \frac{d\left(\tilde{\varepsilon}^{H}+p_{m}^{C} \tilde{n} \tilde{\varepsilon}^{R}\right)}{d p_{m}^{A}}=\frac{d\left[(1+\Lambda) \tilde{\varepsilon}^{H}\right]}{d p_{m}^{A}}>0 .
\end{gathered}
$$

Thus, an increase in $p_{m}^{A}$ raises $\tilde{\varepsilon}^{H}$ and lowers the fertility rate $\tilde{n}$ and the total time allocated to child rearing, $p_{m}^{C} \tilde{n} \tilde{\varepsilon}^{R}$. Given that $\tilde{\varepsilon}^{R}=\Lambda \tilde{\varepsilon}^{H} / p_{m}^{C} \tilde{n}$, and that both $\Lambda \tilde{\varepsilon}^{H}$ and $\tilde{n}$ fall, the effect on $\tilde{\varepsilon}^{R}$ itself is in general ambiguous. But given that total time allocated to own health care and child rearing increases, leisure falls as well.

A higher $p_{m}^{C}$ has no effect on the propensity to save (from (A10)), and no effect on $\Lambda$ (from (A14)). It also has no effect on neither $\tilde{\varepsilon}^{H}$ (from (A16)) nor $\tilde{\varepsilon}^{R}$ (from (A18)), but it reduces $\tilde{n}$ (see (A17)). A marginal increase in the cost of raising children as a proportion of wages, $\theta$, leads ceteris paribus to less children $(d \tilde{n} / d \theta<0)$; it also increases time allocated to child rearing $\left(d \tilde{\varepsilon}^{R} / d \theta>0\right.$, see $\left.(\mathrm{A} 18)\right)$.

To study the dynamics in this economy, substitute first (A10) in (23) with $n_{t}=\tilde{n} \forall t$, to give

$$
K_{t+1}^{P}=N_{t} s_{t}=\sigma(1-\tau)\left(1-\theta p_{m}^{C} \tilde{n}\right) N_{t} a_{t} w_{t}
$$

that is, substituting for $w_{t}$ from (7),

$$
K_{t+1}^{P}=\beta \sigma(1-\tau)\left(1-\theta p_{m}^{C} \tilde{n}\right) Y_{t} .
$$

Similarly, from (7), (18), and (20),

$$
K_{t+1}^{I}=\beta v_{I} \tau Y_{t}
$$

Combined with (A19), this expression yields

$$
k_{t+1}^{I}=\frac{K_{t+1}^{I}}{K_{t+1}^{P}}=\frac{v_{I} \tau}{\sigma(1-\tau)\left(1-\theta p_{m}^{C} \tilde{n}\right)} \equiv J, \quad \forall t .
$$


Using (A17) implies that $J$ does not depend on $p_{m}^{C}$. However, it depends indirectly on $p_{m}^{A}$, through $\sigma$ (see (A10)).

The next step is to calculate $H_{t}^{G} / K_{t}^{P}$, to determine the dynamics of $h_{t}^{A}$ in (A1). From (7), (18), and (21),

$$
H_{t}^{G}=\varphi^{1-\mu}\left(\frac{K_{t}^{I}}{G_{t}^{H}}\right)^{\mu} G_{t}^{H}=\left(\varphi v_{H} \tau \beta\right)^{1-\mu}\left(\frac{K_{t}^{I}}{Y_{t}}\right)^{\mu} Y_{t}
$$

so that

$$
\frac{H_{t}^{G}}{K_{t}^{P}}=\left(\varphi v_{H} \tau \beta\right)^{1-\mu}\left(k_{t}^{I}\right)^{\mu}\left(\frac{Y_{t}}{K_{t}^{P}}\right)^{1-\mu} .
$$

Using (A21), this result can be substituted in (A1) to give, with $\bar{\zeta}=1$ for simplicity,

$$
h_{t+1}^{A}=\frac{\theta\left(\tilde{\varepsilon}^{R}\right)^{\nu_{C}}\left(\tilde{\varepsilon}^{H}\right)^{\nu_{A}}}{\left(\varphi v_{H} \tau \beta\right)^{-\left(1-\nu_{C}\right)(1-\mu)}}\left(h_{t}^{A}\right)^{\kappa} J^{\nu+\mu\left(1-\nu_{C}\right)}\left(\frac{Y_{t}}{K_{t}^{P}}\right)^{\left(1-\nu_{C}\right)(1-\mu)} .
$$

To solve (A23) requires calculating $Y_{t} / K_{t}^{P}$. To do so, note that from (8) and (A21),

$$
\frac{Y_{t}}{K_{t}^{P}}=J^{\alpha}\left(\frac{a_{t}}{x_{t}}\right)^{\beta}
$$

where $x_{t}=K_{t}^{P} / N_{t}$ is the capital-labor ratio. From (10) and (A19),

$$
x_{t+1}=\frac{K_{t+1}^{P}}{N_{t+1}}=\frac{\beta \sigma(1-\tau)\left(1-\theta p_{m}^{C} \tilde{n}\right)}{p_{m}^{C} \tilde{n}}\left(\frac{Y_{t}}{N_{t}}\right) .
$$

By definition, $Y_{t} / N_{t}=\left(Y_{t} / K_{t}^{P}\right) x_{t}$. Using (A24) to substitute for $Y_{t} / K_{t}^{P}$, and (16) to substitute for $a_{t}$, yields

$$
x_{t+1}=\frac{\beta \sigma(1-\tau)\left(1-\theta p_{m}^{C} \tilde{n}\right)}{p_{m}^{C} \tilde{n}} J^{\alpha} q_{t}^{\beta} x_{t}
$$

where $q_{t}=h_{t}^{A} / x_{t}$. Using this definition, equation (A24) can also be written as $Y_{t} / K_{t}^{P}=J^{\alpha} q_{t}^{\beta}$. Substituting this result in (A23) yields

$$
h_{t+1}^{A}=\frac{\theta\left(h_{t}^{A}\right)^{\kappa}}{\left(\varphi v_{H} \tau \beta\right)^{-\left(1-\nu_{C}\right)(1-\mu)}}\left(\tilde{\varepsilon}^{R}\right)^{\nu_{C}}\left(\tilde{\varepsilon}^{H}\right)^{\nu_{A}} J^{\Omega_{1}} q_{t}^{\beta\left(1-\nu_{C}\right)(1-\mu)},
$$

where $\Omega_{1} \equiv \nu+\left(1-\nu_{C}\right)[\mu+\alpha(1-\mu)]>0$. 
Suppose first that $\kappa=1$. Dividing (A27) by (A26) gives

$$
q_{t+1}=\frac{\theta q_{t}^{1-\beta}\left(\tilde{\varepsilon}^{R}\right)^{\nu_{C}}\left(\tilde{\varepsilon}^{H}\right)^{\nu_{A}} J^{\Omega_{1}-\alpha}}{\left(\varphi v_{H} \tau \beta\right)^{-\left(1-\nu_{C}\right)(1-\mu)}}\left\{\frac{\beta \sigma(1-\tau)\left(1-\theta p_{m}^{C} \tilde{n}\right)}{p_{m}^{C} \tilde{n}}\right\}^{-1} q_{t}^{\beta\left(1-\nu_{C}\right)(1-\mu)}
$$

which can be rearranged as

$$
q_{t+1}=\frac{\theta\left(\tilde{\varepsilon}^{R}\right)^{\nu_{C}}\left(\tilde{\varepsilon}^{H}\right)^{\nu_{A}} J^{\Omega_{1}-\alpha}}{\left(\varphi v_{H} \tau \beta\right)^{-\left(1-\nu_{C}\right)(1-\mu)}}\left\{\frac{\beta \sigma(1-\tau)\left(1-\theta p_{m}^{C} \tilde{n}\right)}{p_{m}^{C} \tilde{n}}\right\}^{-1} q_{t}^{\Omega_{2}},
$$

where $\Omega_{2} \equiv 1-\beta\left[1-\beta\left(1-\nu_{C}\right)(1-\mu)\right]>0$ and $\Omega_{1}-\alpha>0$.

Equation (A28) is a linear difference equation in $\hat{q}_{t}=\ln \left(h_{t}^{A} / x_{t}\right)$, whose steady-state solution is

$$
\tilde{q}=\Pi^{1 /\left(1-\Omega_{2}\right)},
$$

where $\Pi$ is the expression that multiplies $q_{t}^{\Omega_{2}}$ in (A28).

Solving equation (A28) yields

$$
\hat{q}_{t}=\left(\frac{1-\Omega_{2}^{t}}{1-\Omega_{2}}\right) \Omega_{2} \ln \Pi+\Omega_{2}^{t} \hat{q}_{0}
$$

Stability requires therefore $\Omega_{2}<1$. Given the definition of $\Omega_{2}$, this condition is always satisfied. Thus, $q_{t}$ converges monotonically to $\tilde{q}$, and the equilibrium is unique.

Equation (8) implies that aggregate output per worker in $t+1$ is

$$
\frac{Y_{t+1}}{N_{t+1}}=\left(\frac{K_{t+1}^{I}}{K_{t+1}^{P}}\right)^{\alpha}\left(\frac{a_{t+1} N_{t+1}}{K_{t+1}^{P}}\right)^{\beta}\left(\frac{K_{t+1}^{P}}{N_{t+1}}\right),
$$

or equivalently, using (A19),

$$
\frac{Y_{t+1}}{N_{t+1}}=\left(k_{t+1}^{I}\right)^{\alpha} q_{t+1}^{\beta} \beta \sigma(1-\tau)\left(1-\theta p_{m}^{C} \tilde{n}\right)\left(\frac{Y_{t}}{N_{t+1}}\right) .
$$

Using (10) and (A21), this implies that the balanced-growth rate of output per worker is

$$
1+\gamma=\frac{\left(v_{I} \tau\right)^{\alpha}}{p_{m}^{C} \tilde{n}} \tilde{q}^{\beta} \beta\left[\sigma(1-\tau)\left(1-\theta p_{m}^{C} \tilde{n}\right)\right]^{1-\alpha} .
$$

Because $q_{t}$ is constant in the steady state, adult health status $h_{t}^{A}$ and the capital-labor ratio $x_{t}$ grow at the same constant rate. From (A25), the 
growth rate of $x_{t}$ is the same as the growth rate of output per worker, and so is the growth rate of $h_{t}^{A}$. From (A20), the growth rate of public capital per worker is also equal to the growth rate of output per worker; from (A21), given that the public-private capital ratio is constant throughout, the stock of private capital per worker also grows at the same rate.

Suppose now that $\kappa<1$. Up to equation (A25), results do not change. ${ }^{42}$ Equation (A26) can be written equivalently as

$$
x_{t+1}=\frac{\beta \sigma(1-\tau)\left(1-\theta p_{m}^{C} \tilde{n}\right)}{p_{m}^{C} \tilde{n}} J^{\alpha}\left(h_{t}^{A}\right)^{\beta} x_{t}^{1-\beta} .
$$

Substituting (A24) in (A23) gives

$$
h_{t+1}^{A}=\frac{\theta\left(\tilde{\varepsilon}^{R}\right)^{\nu_{C}}\left(\tilde{\varepsilon}^{H}\right)^{\nu_{A}}}{\left(\varphi v_{H} \tau \beta\right)^{-\left(1-\nu_{C}\right)(1-\mu)}} J^{\Pi_{1}}\left(h_{t}^{A}\right)^{\Pi_{2}} x_{t}^{\Pi_{3}}
$$

where

$$
\begin{gathered}
\Pi_{1}=\nu+\mu\left(1-\nu_{C}\right)+\alpha\left(1-\nu_{C}\right)(1-\mu)>0, \\
\Pi_{2}=\kappa+\beta\left(1-\nu_{C}\right)(1-\mu)>0, \\
\Pi_{3}=-\beta\left(1-\nu_{C}\right)(1-\mu)=\kappa-\Pi_{2}<0 .
\end{gathered}
$$

I assume that $\Pi_{2}<1$, or equivalently $\kappa<1-\beta\left(1-\nu_{C}\right)(1-\mu)=1-\Pi_{3}$.

Equations (A32) and (A33) form a first-order linear difference equation system in $\hat{h}_{t}^{A}=\ln h_{t}^{A}$ and $\hat{x}_{t}=\ln x_{t}$ which can be written as

$$
\left[\begin{array}{c}
\hat{h}_{t+1}^{A} \\
\hat{x}_{t+1}
\end{array}\right]=\left[\begin{array}{l}
a_{10} \\
a_{20}
\end{array}\right]+\left[\begin{array}{ll}
a_{11} & a_{12} \\
a_{21} & a_{22}
\end{array}\right]\left[\begin{array}{c}
\hat{h}_{t}^{A} \\
\hat{x}_{t}
\end{array}\right],
$$

where

$$
\begin{gathered}
a_{10}=\ln \left\{\frac{\beta \sigma(1-\tau)\left(1-\theta p_{m}^{C} \tilde{n}\right)}{p_{m}^{C} \tilde{n}}\right\}, \\
a_{20}=\ln \left\{\frac{\theta\left(\tilde{\varepsilon}^{R}\right)^{\nu_{C}}\left(\tilde{\varepsilon}^{H}\right)^{\nu_{A}}}{\left(\varphi v_{H} \tau \beta\right)^{-\left(1-\nu_{C}\right)(1-\mu)}} J^{\Pi_{1}}\right\}, \\
a_{11}=\Pi_{2}>0, \quad a_{12}=\Pi_{3}<0, \\
a_{21}=\beta>0, \quad a_{22}=1-\beta>0 .
\end{gathered}
$$

\footnotetext{
${ }^{42}$ In particular, $\kappa<1$ does not affect household decisions, because $a_{t}$ is taken as given from the point of view of decisions taken at $t+1$.
} 
To determine aggregate output per worker in $t+1$, equation (A30) remains as is:

$$
\frac{Y_{t+1}}{N_{t+1}}=J^{\alpha}\left(h_{t+1}^{A}\right)^{\beta} x_{t+1}^{1-\beta} .
$$

Using (10), (16), and (A19) yields

$$
\frac{Y_{t+1}}{N_{t+1}}=J^{\alpha}\left(h_{t+1}^{A}\right)^{\beta} x_{t+1}^{-\beta} \beta \sigma(1-\tau)\left(1-\theta p_{m}^{C} \tilde{n}\right)\left(\frac{Y_{t}}{p_{m}^{C} \tilde{n} N_{t}}\right) .
$$

Using (A21), the balanced-growth rate of output per worker is now

$$
1+\gamma=\frac{\left(v_{I} \tau\right)^{\alpha}}{p_{m}^{C} \tilde{n}}\left(\tilde{h}^{A}\right)^{\beta} \tilde{x}^{-\beta} \beta\left[\sigma(1-\tau)\left(1-\theta p_{m}^{C} \tilde{n}\right)\right]^{1-\alpha},
$$

where $\tilde{h}^{A}$ and $\tilde{x}$ are given by, using (A21) and setting $\Delta h_{t+1}^{A}=\Delta x_{t+1}=0$ in (A32) and (A33),

$$
\begin{gathered}
\tilde{x}=\left\{\frac{\left(v_{I} \tau\right)^{\alpha}}{p_{m}^{C} \tilde{n}} \beta\left[\sigma(1-\tau)\left(1-\theta p_{m}^{C} \tilde{n}\right)\right]^{1-\alpha}\right\}^{1 / \beta} \tilde{h}^{A}, \\
\tilde{h}^{A}=\left\{\frac{\theta\left(\tilde{\varepsilon}^{R}\right)^{\nu_{C}}\left(\tilde{\varepsilon}^{H}\right)^{\nu_{A}}}{\left(\varphi v_{H} \tau \beta\right)^{-\left(1-\nu_{C}\right)(1-\mu)}} J^{\Pi_{1}}\right\}^{1 /\left(1-\Pi_{2}\right)} \tilde{x}^{\Pi_{3} /\left(1-\Pi_{2}\right)},
\end{gathered}
$$

These equations define the steady-state relationships between $h_{t}^{A}$ and $x_{t}$. Equation (A37) defines a straight line with positive slope depicted as $K K$ in Figure 1. To determine the slope of the curve defined by (A38), we need to determine the sign of $\left(1-\Pi_{2}\right) / \Pi_{3}$. From the above definitions,

$$
\frac{1-\Pi_{2}}{\Pi_{3}}=\frac{1-\Pi_{2}}{\kappa-\Pi_{2}}=-\frac{1-\kappa-\beta\left(1-\nu_{C}\right)(1-\mu)}{\beta\left(1-\nu_{C}\right)(1-\mu)}<0
$$

given Assumption 2. Equation (A38) is depicted as the downward-sloping convex curve $H H$ in Figure 1.

As illustrated in the figure, the system (A32)-(A33) has a unique equilibrium. To examine its stability in the vicinity of that equilibrium, let $\mathbf{A}$ denote the matrix of coefficients in (A34) and let $\operatorname{det} \mathbf{A}$ denote its determinant and $\operatorname{tr} \mathbf{A}$ its trace. Let $\lambda_{j}, j=1,2$ denote the eigenvalues of $\mathbf{A}$; the characteristic polynomial is thus $p(\lambda)=\lambda^{2}-\lambda \operatorname{tr} \mathbf{A}+\operatorname{det} \mathbf{A}$. Thus, $p(1)=1-\operatorname{tr} \mathbf{A}+\operatorname{det} \mathbf{A}$, whereas $p(-1)=1+\operatorname{tr} \mathbf{A}+\operatorname{det} \mathbf{A}$. 
From the above definitions,

$$
\begin{gathered}
\operatorname{tr} \mathbf{A}=1-\beta+\Pi_{2}>0, \\
\operatorname{det} \mathbf{A}=(1-\beta) \Pi_{2}-\beta\left(\kappa-\Pi_{2}\right)>0 .
\end{gathered}
$$

Given the signs of $\operatorname{tr} \mathbf{A}=\lambda_{1}+\lambda_{2}$ and $\operatorname{det} \mathbf{A}=\lambda_{1} \lambda_{2}$, it is clear that $p(-1)>0$. We also have

$$
p(1)=1-1+\beta-\Pi_{2}+(1-\beta) \Pi_{2}-\beta\left(\kappa-\Pi_{2}\right)
$$

so that

$$
p(1)=\beta(1-\kappa)>0 .
$$

Given that $\operatorname{tr} \mathbf{A} \in(-2,2)$ and $\operatorname{det} \mathbf{A} \in(-1,1)$, both eigenvalues $\in(-1,1)$; given that $\operatorname{tr} \mathbf{A}>0, \operatorname{det} \mathbf{A}>0$, they are not only less than unity in absolute terms but actually positive. The steady state is thus a sink (see Azariadis (1993, p. 65)). 


\section{References}

African Union, Transport and the Millennium Development Goals, Addis Ababa (February 2005).

Agénor, Pierre-Richard, "A Theory of Infrastructure-Led Development," Working Paper No. 83, Centre for Growth and Business Cycle Research, University of Manchester (December 2006).

—, "Health and Infrastructure in a Model of Endogenous Growth," Journal of Macroeconomics, 30 (December 2008), 1407-22.

- Public Capital, Growth, and Welfare, work in progress, University of Manchester (January 2009).

Agénor, Pierre-Richard, and Madina Agénor, "Infrastructure, Women's Time Allocation, and Economic Development," unpublished, University of Manchester and Harvard School of Public Health (January 2009).

Agénor, Pierre-Richard, and Kyriakos Neanidis, "The Allocation of Public Expenditure and Economic Growth," Working Paper No. 69, Centre for Growth and Business Cycle Research, University of Manchester (March 2006).

Ashraf, Quamrul, Ashley Lester, and David Weil, "When Does Improving Health Raise GDP?," Working Paper No 2008-7, Brown University (June 2008).

Azariadis, Costas, Intertemporal Macroeconomics, Blackwell Publishers (Oxford: 1993).

Barro, Robert J, and Gary S. Becker, "Fertility Choice in a Model of Economic Growth," Econometrica, 57 (March 1989), 481-501.

Becker, Gary S., "Health as Human Capital: Synthesis and Extensions," Oxford Economic Papers, 59 (July 2007), 379-410.

Behrman, Jere, "The Impact of Health and Nutrition on Education," World Bank Research Observer, 11 (- 1996), 23-37.

Currie, Janet "Child Health in Developed Countries," in Handbook of Health Economics, Vol. 1B, ed. by A. Culyer and J. Newhouse, North Holland (Amsterdam: 2000).

__ , "Healthy, Wealthy and Wise: Socioeconomic Status, Poor Health in Childhood, and Human Capital Development," Workin Paper No 13987, National Bureau of Economic Research (May 2008). Forthcoming: Journal of Economic Literature. 
Bhattacharya, Joydeep, and Xue Qiao, "Public and Private Expenditures on Health in a Growth Model," Journal of Economic Dynamics and Control, 31 (August 2007), 2519-35.

Blackburn. Keith, and Giam P. Cipriani, "A Model of Longevity and Growth," Journal of Economic Dynamics and Control," 26 (February 2002), 187-204.

Bloom, David, and David Canning, "Schooling, Health, and Economic Growth: Reconciling the Micro and Macro Evidence," unpublished, Harvard School of Public Health (February 2005).

Boucekkine, Raouf, Rodolphe Desbordes, and Hélène Latzer, "How do Epidemics Induce Behavioral Changes?," unpublished, Université Catholique de Louvain (May 2008).

Case, Anne, D. Lubotsky, and Christina Paxson, "Economic Status and Health in Childhood: The Origins of the Gradient," American Economic Review, 92 (December 2002), 1308-34.

Case, Anne, Angela Fertig, and Christina Paxson, "The Lasting Impact of Childhood Health and Circumstance," Journal of Health Economics, 24 (March 2005), 365-89.

Castelló-Climent, Amparo, and Rafael Doménech, "Human Capital Inequality, Life Expectancy and Economic Growth," Economic Journal, 118 (April 2008), 653-77.

Caulfield, Laura E., Mercedes de Onis, Monika Bloessner, and Robert E. Black, "Undernutrition as an Underlying Cause of Child Deaths Associated with Diarrhea, Pneumonia, Malaria, and Measles," American Journal of Clinical Nutrition, 80 (July 2004),193-98.

Cervellati, Matteo, and Uwe Sunde, "Human Capital, Life Expectancy, and the Process of Economic Development," American Economic Review, 95 (December 2005), 1653-72.

Chakraborty, Shankha, "Endogenous Lifetime and Economic Growth," Journal of Economic Theory, 116 (May 2004), 119-37.

Cutler, David M., Angus Deaton, and Adriana Lleras-Muney "The Determinants of Mortality," Journal of Economic Perspectives, 20 (June 2006), 97-120.

Deaton, Angus, "Health, Inequality, and Economic Development," Journal of Economic Literature, 41 (March 2003), 113-58.

Finlay, Jocelyn, "Endogenous Longevity and Economic Growth," unpublished, 
Australian National University (February 2006).

—_, "The Role of Health in Economic Development," PGDA Working Paper No. 21, Harvard School of Public Health (March 2007).

Galor, Oded, and David Mayer-Foulkes, "Food for Thought: Basic Needs and Persistent Educational Inequality," unpublished, Brown University (June 2004).

Galor, Oded, and David N. Weil, "Population, Technology, and Growth: From the Malthusian Regime to the Demographic Transition and Beyond," American Economic Review, 90 (September 2000), 806-28.

Gertler, Paul, "Water for Life: The Impact of Water Supply Privatization on Child Mortality," Journal of Political Economy, 113 (February 2005), 83-120.

Gertler, Paul, and Jenifer Zeitlin, "The Returns to Childhood Investments in terms of Health later in Life," in Health and Health Care in Asia, ed. by Teh-Wei Hu and H- Cheen, Oxford University Press (Oxford: 1996).

—, "Do Childhood Investments in Education and Nutrition Improve Adult Health in Indonesia?," in The Economics of Health care in Asia-Pacific Countries, ed. by Teh-Wei Hu, E. Elgar (Cheltenham: 2002).

Grossman, Michael, "On the Concept of Health Capital and the Demand for Health," Journal of Political Economy, 80 (March 1972), 223-55.

Hashimoto, Ken-ichi, and Ken Tabata, "Health Infrastructure, Demographic Transition and Growth," Review of Development Economics, 9 (November 2005), 549-62.

Hazan, Moshe, and Hosny Zoabi, "Does Longevity Cause Growth?," Journal of Economic Growth, 11 (December 2006), 363-76.

Ilahi, Nadeem, "The Intra-Household Allocation of Time and Tasks: What have we Learned from the Empirical Literature?," Policy Research Report on Gender and Development No. 13, World Bank (June 2000).

Jeon, Yongil, Sang-Young Rhyu, and Michael P. Shields, "Fertility in SubSaharan African Countries with Consideration to Health and Poverty," IZA Discussion Paper No. 3526 (June 2008).

Kalemli-Ozcan, Sebnem, "A Stochastic Model of Mortality, Fertility, and Human Capital Investment," Journal of Development Economics, 70 (February 2003), 103-18.

— , "The Uncertain Lifetime and the Timing of Human Capital Investment," 
Journal of Population Economics, 21 (July 2008), 557-72.

Kohler, Iliana, and Beth J. Soldo, "Early Life Events and Health Outcomes in Late Life in Developing Countries - Evidence from the Mexican Health and Aging Study," unpublished, University of Pennsylvania (March 2004).

Kooreman, Peter and Arie Kapteyn, "A Disaggregated Analysis of the Allocation of Time within the Household," Journal of Political Economy, 95 (April 1987), 223-49.

Levy, Hernan, "Rural Roads and Poverty Alleviation in Morocco," unpublished, World Bank (May 2004).

Lorentzen, Peter, John McMillan, and Romain Wacziarg, "Death and Development," Journal of Economic Growth, 13 (June 2008), 81-124.

Mayer-Foulkes, David, "Human Development Traps and Economic Growth," in Health and Economic Growth: Findings and Policy Implications, ed. by Guillem López-Casasnovas, Berta Rivera and Luis Currais, MIT Press (Boston, Mass.: 2005).

Miguel, Edward, "Health, Education, and Economic Development," in Health and Economic Growth: Findings and Policy Implications, ed. by Guillem López-Casasnovas, Berta Rivera and Luis Currais, MIT Press (Boston, Mass.: 2005).

Mullahy, John, and Stephanie A. Robert, "No Time to Lose? Time Constraints and Physical Activity," Working Paper No. 14513, National Bureau of Economic Research (November 2008).

Nankhuni, Flora, and Jill Findeis, "The Effects of Environmental Degradation on Women's and Children's Time Allocation Decisions in Malawi: Impact on Children's Welfare," unpublished, Pennsylvania State University (May 2003).

Oreopoulos, Philip, Mark Stabile, Rand Walld, and Leslie Roos, "Short, Medium, and Long-Term Consequences of Poor Infant Health: An Analysis using Siblings and Twins," Journal of Human Resources, 43 (March 2008), 88-138.

Osang, Thomas, and Jayanta Sarkar, "Endogenous Mortality, Human Capital and Endogenous Growth." Journal of Macroeconomics, 30 (December 2008), 1423-45.

Paxson, Christina H., and Norbert Schady, "Cognitive Development among Young Children in Ecuador: The Roles of Wealth, Health and Parenting," 
Journal of Human Resources, 42 (March 2007), 49-84.

Pelletier, D. L., E. A. Frongillo, J-P. Habicht, "Epidemiologic Evidence for a Potentiating Effect of Malnutrition on Child Mortality," American Journal of Public Health, 83 (December 2003), 1130-33.

Powdthavee, Nattavudh, and Anna Vignoles, "Mental Health of Parents and Life Satisfaction of Children: A Within-Family Analysis of Intergenerational Transmission of Well-Being," Discussion Paper No. 2008/20, University of York (July 2008).

Salm, Martin, and Daniel Schunk, "The Role of Childhood Health for the Intergenerational Transmission of Human Capital: Evidence from Administrative Data," IZA Discussion Paper No. 3646 (August 2008).

Shi, Anqing, "How Access to Urban Potable Water and Sewerage Connections Affect Child Mortality," Policy Research Working Paper No. 2274, World Bank (January 2000).

Silles, Mary A., "The Causal Effect of Education on Health: Evidence from the United Kingdom," Economics of Education Review, 28 (February 2009), $122-28$.

Smith, James P., "The Impact of Childhood Health on Adult Labor Market Outcomes," Working Paper No. 2008-14, University College Dublin (April 2008).

Soares, Rodrigo R., "The Effect of Longevity on Schooling and Fertility: Evidence from the Brazilian Demographic and Health Survey," Journal of Population Economics, 19 (February 2006), 71-97.

Strauss, John, and Duncan Thomas, "Health, Nutrition and Economic Development," Journal of Economic Literature, 36 (June 1998), 766-817.

Tang, Kam Ki, and Jie Zhang, "Health, Education, and Life Cycle Savings in the Development Process," Economic Inquiry, 45 (July 2007), 615-30.

Taylor, Beck A., Eric Dearing, and Kathleen McCartney, "Incomes and Outcomes in Early Childhood," Journal of Human Resources, 39 (December 2004), 980-1007.

Wagstaff, Adam, and Mariam Claeson, The Millennium Development Goals for Heath: Rising to the Challenges, World Bank (Washington DC: 2004).

Wang, Limin, "Determinants of Child Mortality in LDCs: Empirical Findings from Demographic and Health Surveys," Health Policy, 65 (September 2003), 
277-99.

Weiss, John, "Infrastructure and Economic Development," Economic Research Paper No. 50, African Development Bank (March 1999).

World Bank, The Welfare Impact of Rural Electrification: A Reassessment of the Costs and Benefits, Independent Evaluation Group, World Bank (Washington DC: 2008).

World Health Organization, The World Health Report 2000-Health Systems: Improving Performance, WHO Publications (Geneva: 2000).

Zhang, Jie, Junsen Zhang, and Ronald Lee, "Rising Longevity, Education, Savings, and Growth," Journal of Development Economics, 70 (February 2003), 83-101.

Zhang, Junsen, and Jie Zhang, "The Effect of Life Expectancy on Fertility, Saving, Schooling and Economic Growth: Theory and Evidence," Scandinavian Journal of Economics, 107 (March 2005), 45-66. 
Figure 1

Equilibrium with Decreasing Returns to Parent's Health

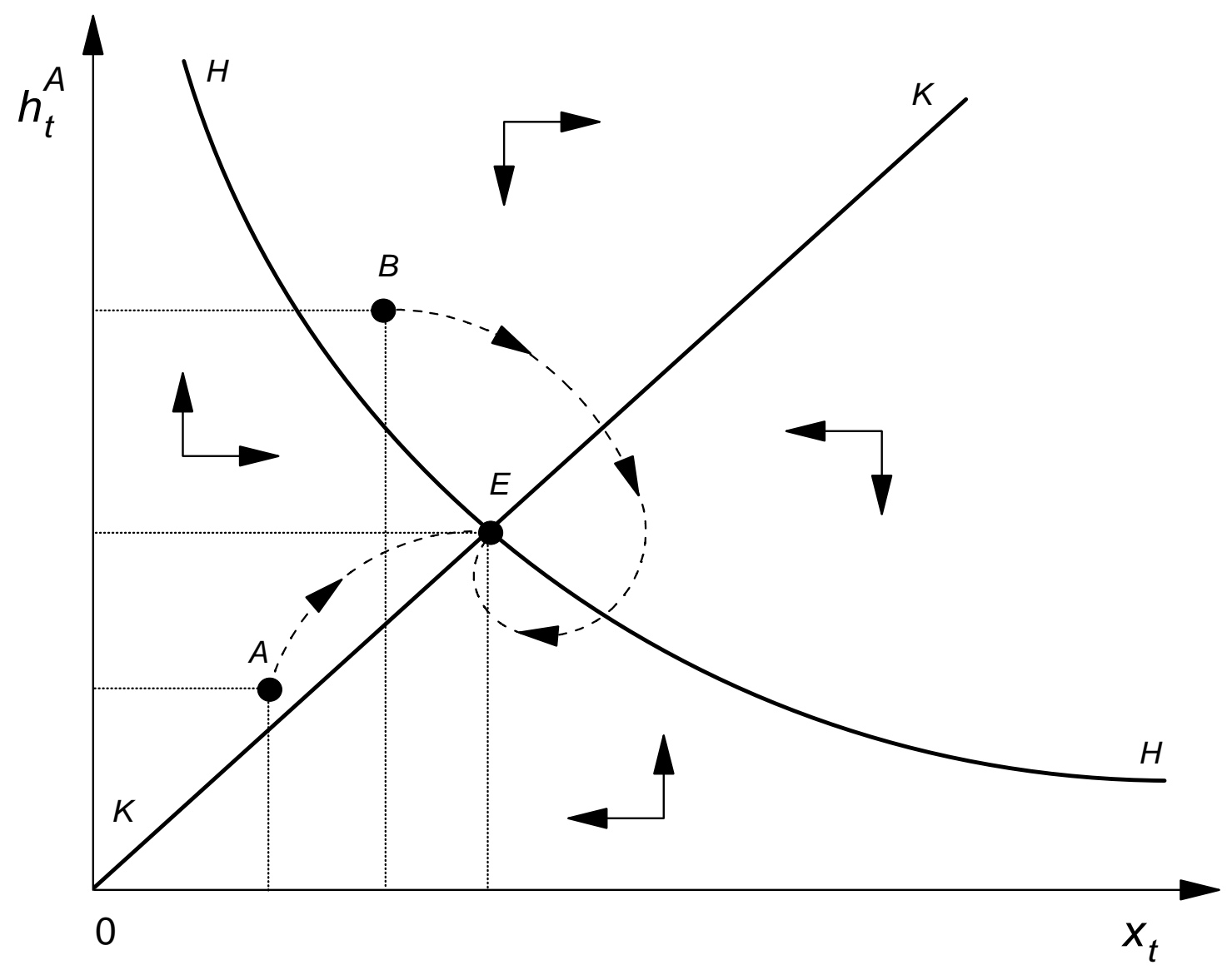


Figure 2

Increase in Adult Survival Rate

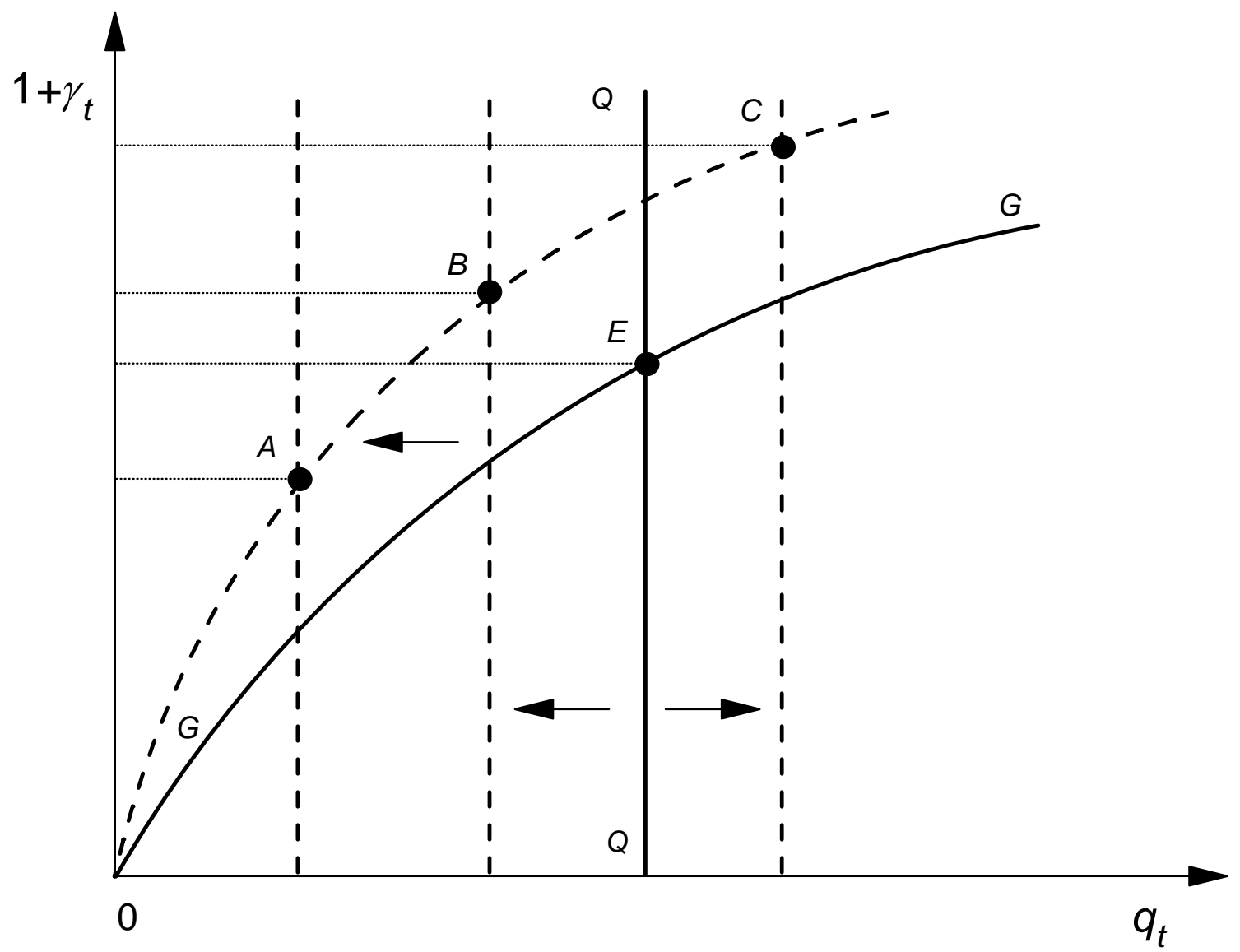


Figure 3

Threshold Effects

with Endogenous Adult Survival Rate

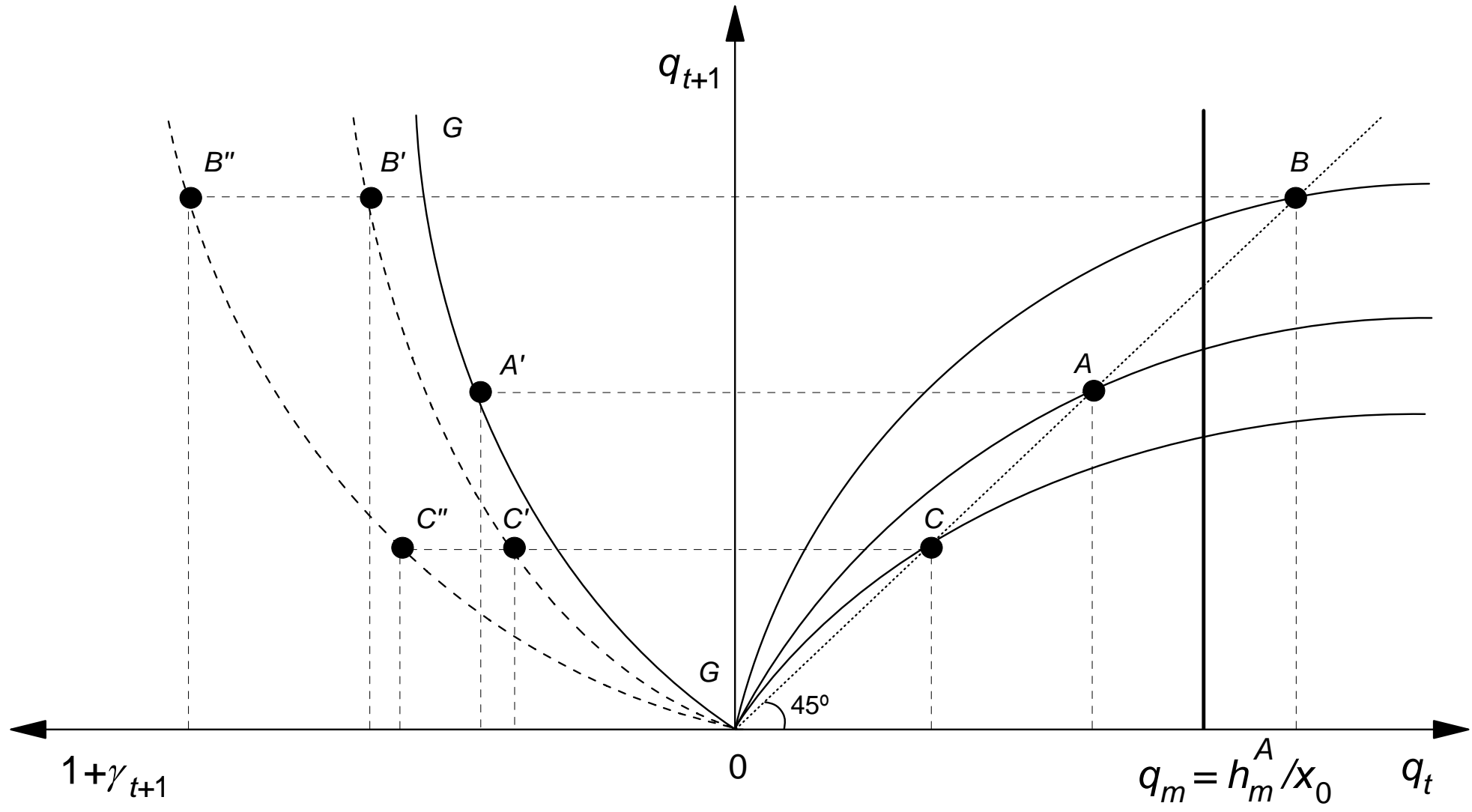


Figure 4

Health Status and the Adult Survival Rate

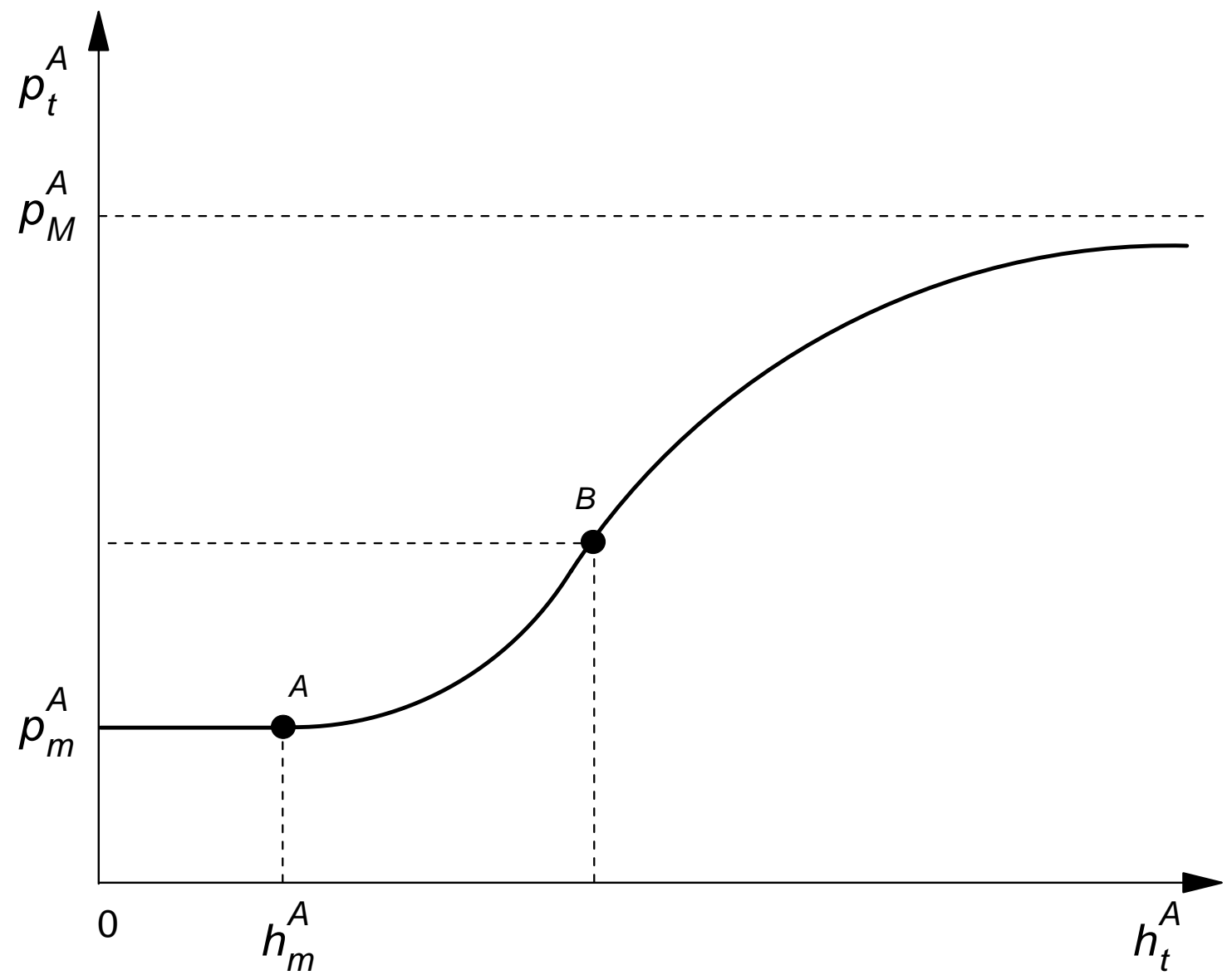

